Origin of Conductive Nanocrystalline Diamond Nanoneedles for Optoelectronic Applications

Peer-reviewed author version

KAMATCHI JOTHIRAMALINGAM, Sankaran; Yeh, Chien-Jui; Hsieh, Ping-Yen; POBEDINSKAS, Paulius; Kunuku, Srinivasu; Leou, Keh-Chyang; Tai, Nyan-Hwa; Lin, I-Nan \& HAENEN, Ken (2019) Origin of Conductive Nanocrystalline Diamond Nanoneedles for Optoelectronic Applications. In: ACS APPLIED MATERIALS \& INTERFACES, 11(28), p. 25388-25398.

DOI: 10.1021/acsami.9b05469

Handle: http://hdl.handle.net/1942/29178 


\section{Origin of Conductive Nanocrystalline Diamond Nanoneedles for Optoelectronic Applications}

Kamatchi Jothiramalingam Sankaran, ${ }^{, \dagger, \ddagger}$ Chien-Jui Yeh, ${ }^{\S}$ Ping-Yen Hsieh, " Paulius Pobedinskas, ${ }^{\dagger, \ddagger}$ Srinivasu Kunuku, ${ }^{\S}$ Keh-Chyang Leou, ${ }^{\S}$ Nyan-Hwa Tai," I-Nan Lin, ${ }^{€}$ and Ken Haenen*,†,

${ }^{\dagger}$ Institute for Materials Research (IMO), Hasselt University, Diepenbeek, 3590 Belgium.

${ }^{\ddagger}$ IMOMEC, IMEC vzw, Diepenbeek, 3590 Belgium.

$\S^{\S}$ Department of Engineering and System Science, National Tsing Hua University, Hsinchu 30013, Taiwan, Republic of China.

"Department of Materials Science and Engineering, National Tsing Hua University, Hsinchu 30013, Taiwan, Republic of China.

${ }^{\epsilon}$ Department of Physics, Tamkang University, Tamsui 251, Taiwan, Republic of China.

ABSTRACT: Microstructural evolution of nanocrystalline diamond (NCD) nanoneedles owing to the addition of methane and nitrogen in the reactant gases is systematically accessed. It has been determined that by varying the concentration of $\mathrm{CH}_{4}$ in the $\mathrm{CH}_{4} / \mathrm{H}_{2} / \mathrm{N}_{2}$ plasma is significant to tailor the morphology and microstructure of NCD films. While NCD films grown with $1 \% \mathrm{CH}_{4}$ in a $\mathrm{CH}_{4} / \mathrm{H}_{2} / \mathrm{N}_{2}$ (3\%) plasma contain large diamond grains, the microstructure changed considerably for NCD films grown using $5 \%$ (or $10 \%$ ) $\mathrm{CH}_{4}$, ensuing in nano-sized diamond grains. For $15 \%$ $\mathrm{CH}_{4}$ grown NCD films, a well-defined nanoneedle structure evolves. These NCD nanoneedle films contain $s p^{3}$ phase diamond, sheathed with $s p^{2}$ bonded graphitic phases, achieving a low resistivity of $90 \Omega \cdot \mathrm{cm}$ and enhanced field electron emission (FEE) properties, namely, a low turn-on field of 
4.3 V/ $\mu \mathrm{m}$ with a high FEE current density of $3.3 \mathrm{~mA} / \mathrm{cm}^{2}$ (at an applied field of $8.6 \mathrm{~V} / \mu \mathrm{m}$ ) and a significant field enhancement factor of 3865. Furthermore, a microplasma device utilizing NCD nanoneedle films as cathodes can trigger a gas breakdown at a low threshold field of $3600 \mathrm{~V} / \mathrm{cm}$ attaining a high plasma illumination current density of $1.14 \mathrm{~mA} / \mathrm{cm}^{2}$ at an applied voltage of 500 $\mathrm{V}$ and a high plasma lifetime stability of 881 min was evidenced. The optical emission spectroscopy studies suggest that the $\mathrm{C}_{2}, \mathrm{CN}$ and $\mathrm{CH}$ species in the growing plasma are the major causes for the observed microstructural evolution in the NCD films. However, the increase in substrate temperature to a value of $\sim 780{ }^{\circ} \mathrm{C}$ due to the incorporation of $15 \% \mathrm{CH}_{4}$ in the $\mathrm{CH}_{4} / \mathrm{H}_{2} / \mathrm{N}_{2}$ plasma, is the key driver resulting in the origin of nanoneedles in NCD films. The outstanding optoelectronic characteristics of these nanoneedle films make them suitable as cathodes in high brightness display panels.

KEYWORDS: nanocrystalline diamond nanoneedles, electrical resistivity, field electron emission, plasma illumination, microstructural evolution, transmission electron microscopy, optical emission spectroscopy

\section{- INTRODUCTION}

Field electron emitters with applicable electron emission characteristics, for example low turn-on field, steady and high current density and large field enhancement factor, catch potential applications as flat panel displays, cathodes in X-rays, vacuum microelectronic devices and microplasma devices. ${ }^{1-3}$ Nanocarbon materials, including carbon nanotubes, ${ }^{4}$ graphene, ${ }^{5}$ tetrahedral amorphous carbon $(a-C),{ }^{6}$ diamond-like carbon, ${ }^{7}$ and diamond ${ }^{8}$ have been comprehensively investigated for the exploitation of field electron emission (FEE). Among carbon based field emitters, diamond possesses excellent FEE characteristics owing to its strong bonding 
structure, low electron affinity, good electrical and thermal conductivities, and utmost hardness to withstand ion bombardment. ${ }^{9,10}$

During the 1990s, the diamond based FEE studies were accomplished on materials deposited using $\mathrm{CH}_{4} / \mathrm{H}_{2}$ plasmas, which resulted the deposition of microcrystalline diamond (MCD) films of grain sizes ranging from $0.1 \mu \mathrm{m}$ to several tens of microns. The large diamond grains, whose properties resemble those of monocrystalline diamond, have a large electronic band gap hindering the FEE behavior of the MCD films because of a shortage of the electrons required for field emission. ${ }^{11}$ Ultimately, it was found that the grain size could be varied with the deposition parameters as the constituents in the reaction gases. The promising method to achieve enhanced FEE properties of diamond is to reduce the diamond grain size, which may result in the improvement of the conducting pathways through an increase in the proportion of grain boundaries.

On the other hand, excellent field emitters have gain attention in recent time owing to their potential for reliable incorporation in optoelectronic devices. Mainly, microplasma device is based on photonics technology that units materials science, optoelectronics and plasma science. These devices possess promising applications such as microplasma display panels, detectors for toxic gases, ozone production and several biomedical and bioelectronic applications. ${ }^{12,13}$ Cold cathode materials such as CNTs, Si, Mo and ZnO are used as cathodes in microplasma devices and attain electron emission excellently. ${ }^{14-16}$ Conversely, these materials in the microplasma devices show poor lifetime issues ${ }^{17,18}$ as these materials are exposed to plasma ion bombardment, the harshest environment, continuously while operating the microplasma devices. Hence, a material with better robustic and high secondary electron emission efficiency is essential to act as a microplasma 
device's cathode. Theoretical studies reported that a superior FEE material can show a better performance in a microplasma device when it is utilized as a cathode. ${ }^{19,20}$

Nanocrystalline diamond (NCD) films containing 10-100 nm sized diamond grains were synthesized by the addition of noble gases in the $\mathrm{CH}_{4} / \mathrm{H}_{2}$ microwave plasma. ${ }^{11,20-23}$ Especially, addition of Ar leading to a $\mathrm{H}_{2}$-deficient plasma enhances the electron density and modifies the diamond film morphology from MCD to NCD (or ultra-nanocrystalline diamond (UNCD)) films. ${ }^{21-24}$ The transition in microstructure was proposed induced by changing the growth mechanism governed by $\mathrm{CH}_{3}$ species in a $\mathrm{CH}_{4} / \mathrm{H}_{2}$ plasma ${ }^{25,26}$ to $\mathrm{C}_{2}$ as a growth species in $\mathrm{CH}_{4} / \mathrm{Ar}$ plasma. ${ }^{27,28}$ The decrease in grain size of diamond in the NCD film enhances the proportion of non-diamond carbon in the grain boundaries and hence it shows better FEE properties than the MCD films. ${ }^{29}$

Nevertheless, the NCD films are not conducting enough because non-diamond carbon, i.e. $a-C$, exists in the grain boundaries limiting the FEE properties. ${ }^{30}$ Conversely, nanographites are formed in the grain boundaries of the NCD films by incorporating $\mathrm{N}_{2}$ in a $\mathrm{CH}_{4} / \mathrm{Ar}$ plasma, demonstrating an increase in the electrical conductivity as well as enhanced FEE properties. ${ }^{31-33}$ Moreover, said nitrogen inclusion has a strong effect on the observed film morphology containing one dimensional (1D) diamond nanostructures like diamond nanowires. ${ }^{34-36}$ These nanowires consist of a diamond core sheathed with $s p^{2}$-bonded carbon of a few nanometers in thickness.

Numerous reports have revealed that a transition from MCD to NCD grains is observed when the concentration of $\mathrm{CH}_{4}$ in the growth plasma increases. ${ }^{37-39}$ Methane affords carbon source for the diamond growth, on the other hand it also plays a vital part for the formation of diamond nanostructures. ${ }^{39,40}$ This paper investigates in detail the evolution of NCD nanoneedle and its microstructure by varying the concentration of $\mathrm{CH}_{4}$ in $\mathrm{CH}_{4} / \mathrm{H}_{2} / \mathrm{N}_{2}$ gas mixtures. The modification 
in the microstructure causes the influence in FEE and plasma illumination (PI) characteristics, is emphasized. The factors leading to the origin of such nanoneedles have been examined by optical emission spectroscopy (OES). From OES studies, it is observed that the $\mathrm{CN}$ and $\mathrm{C}_{2}$ emission lines are revealed to be the significant factors for the formation of nanoneedles. The link between said species and the diamond growth behavior is conversed.

\section{- EXPERIMENTAL METHODS}

(100) silicon substrates were utilized to synthesize NCD films. A 6-7 nm sized ultradispersed detonation nanodiamond contained in a water-based colloidal suspension were seeded on the Si substrates using spin-coating method. ${ }^{41}$ An ASTeX 6500 series microwave plasma enhanced chemical vapor deposition (MWPECVD) reactor was employed to synthesize NCD films on the seeded silicon substrates using $\mathrm{CH}_{4}, \mathrm{H}_{2}$ and $\mathrm{N}_{2}$ gas mixtures for $60 \mathrm{~min}$. The pressure and microwave power were kept at 65 Torr and $3000 \mathrm{~W}$, respectively. During NCD growth the $\mathrm{N}_{2}$ concentration was retained constant at 3\% $(9 \mathrm{sccm})$, the concentration of $\mathrm{CH}_{4}$ was changed from $1 \%$ (3 sccm) to $15 \%(45 \mathrm{sccm})$ and supplemented by $\mathrm{H}_{2}$ to reach a total flow rate of $300 \mathrm{sccm}$ (standard cubic centimeter). The samples were named as " $\mathrm{NCD}_{\mathrm{z}}$ " films, where $\mathrm{z}$ is the percentage of $\mathrm{CH}_{4}$ changing from 1 to $15 \%$ in the gas phase. The substrates were solely heated because the plasma species were bombarded in the plasma. The substrate temperature was evaluated by a single color optical pyrometer of optical emission coefficient $=0.3$.

The surface morphology, crystalline quality, microstructure and bonding structure of the NCD films were characterized using a FEI Quanta 200 FEG scanning electron microscope (SEM) operated at $15 \mathrm{kV}$, a Horiba Jobin Yvon T64000 Raman spectrometer equipped with a BXFM Olympus 9/128 microscope in combination with a Horiba JY Symphony CCD detector with a 488 nm Lexell SHG laser, a transmission electron microscopy (TEM, Joel 2100F) and an electron 
energy loss spectroscopy (EELS, Gatan Enfina) combined with TEM, respectively. An in situ optical emission spectroscopy (OES; AvaSpec-2048 (Avantes)) equipped with an optical fiber (Avantes FC UV600-2) was used to characterize the constituents in the plasma. A four-point probe technique was employed to evaluate the electrical resistivity of the NCD films.

The room temperature FEE characteristics of the $\mathrm{NCD}_{\mathrm{z}}$ films were evaluated by a tunable parallel-plate setup in vacuum of below $10^{-6}$ Torr. A Mo-rod (3 mm in diameter) was applied as an anode. The cathode-to-anode distance was maintained by a micrometer and the distance measured was about $60 \mu \mathrm{m}$. The current-voltage $(I-V)$ characteristics was measured by a Keithley 237 electrometer. A microplasma device with a parallel-plate setup was fabricated to illustrate the PI properties of the films. The cathode was the NCD films and the anode was indium-tin oxide (ITO) coated glass, which were separated by a $1.0 \mathrm{~mm}$ thick polytetrafluoroethylene (Teflon) spacer. An $8 \mathrm{~mm}$ diameter circular hole was made in the spacer to form a cylindrical cavity. A DC voltage is applied to ignite the plasma in Ar atmosphere of pressure 50 Torr. A Keithley 2410 electrometer was employed to acquire the current-voltage $(I-V)$ characteristics.

\section{- RESULTS AND DISCUSSION}

SEM micrographs in Figure 1a-d show the modification of surface morphology of the NCD films with increase in the concentration of $\mathrm{CH}_{4}$ in the $\mathrm{CH}_{4} / \mathrm{H}_{2} / \mathrm{N}_{2}$ microwave plasma. Figure 1a clearly reveals that the $\mathrm{NCD}_{1}$ films contain randomly oriented large diamond grains of size $\sim 600 \mathrm{~nm}$ with very rough surface and evidently distinguishable edges and facets. The substrate temperature measured during the growth of such films is $\sim 540^{\circ} \mathrm{C}$ (curve I, Figure 1e). Figure 1b and c show that when the $\mathrm{CH}_{4}$ concentration was increased to $5 \%\left(\mathrm{NCD}_{5}\right)$ or $10 \%\left(\mathrm{NCD}_{10}\right)$, the micron sized faceted grains were disappeared and cauliflower-like morphological grains were appeared with a size of about $200 \mathrm{~nm}$ going down to $20 \mathrm{~nm}$ when the substrate temperature raises from $\sim 650{ }^{\circ} \mathrm{C}$ to 
$710^{\circ} \mathrm{C}$ (curve I, Figure 1e) respectively for $\mathrm{NCD}_{5}$ and $\mathrm{NCD}_{10}$ films. Rakha et al. ${ }^{40}$ also reported such a granular structure evolutionary behavior, i.e., the $\mathrm{CH}_{4} / \mathrm{H}_{2} / \mathrm{Ar}$ plasma grown diamond films encountered a reduction in grain size with the increase in $\mathrm{CH}_{4}$ concentration. However, for $15 \%$ $\mathrm{CH}_{4}$-content $\mathrm{NCD}$ films ( $\mathrm{NCD}_{15}$ ), the grains achieve a distinctly different randomly oriented onedimensional (1D) needle structure (Figure 1d). The nanonenedles are 50-250 nm in length and diameter of few nanometers. The growth temperature at which these structures were obtained, is $\sim 780^{\circ} \mathrm{C}$ (curve I, Figure 1e). The $\mathrm{NCD}_{15}$ films with nanoneedles are hereafter denoted as “nanocrystalline diamond nanoneedle (NDNN) films" in the following sections of this paper.

Furthermore, the growth rate of the NCD films also changed markedly on the increase in $\mathrm{CH}_{4}$ concentration, which was analyzed from the cross-sectional SEM micrographs (insets of Figure 1a-d). Figure 1e displays that the growth rate is $9.16 \pm 0.7 \mathrm{~nm} / \mathrm{min}$ for $\mathrm{NCD}_{1}$ films and increases monotonously because of the increase of $\mathrm{CH}_{4}$ in the plasma (curve II, Figure 1e). The $\mathrm{NCD}_{5}$ films show a growth rate of $21.6 \pm 0.6 \mathrm{~nm} / \mathrm{min}$, while $\mathrm{NCD}_{10}$ and NDNN films show $30.0 \pm 0.4 \mathrm{~nm} / \mathrm{min}$ and $33.5 \pm 0.9 \mathrm{~nm} / \mathrm{min}$, respectively. The increase in the growth rate can be understand by the increase in carbonaceous species, which is well supported by previous findings, ${ }^{39,42}$ the drastic modification in granular structure for NDNN films is quite unexpected.

The bonding characteristics of the $\mathrm{NCD}_{\mathrm{z}}$ films was studied by Raman spectroscopy. Figure 2a illustrates the Raman spectra of the $\mathrm{NCD}_{\mathrm{z}}$ films. The spectrum corresponding to $\mathrm{NCD}_{1}$ films (spectrum I, Figure 2a) displays a sharp Raman peak at $1334 \mathrm{~cm}^{-1}$ (“dia”), which reflects the large grain size of diamond for these materials. Increasing the $\mathrm{CH}_{4}$ concentration to $5 \%$ in the $\mathrm{CH}_{4} / \mathrm{H}_{2} / \mathrm{N}_{2}$ plasma ensues in the shrinking of the $1334 \mathrm{~cm}^{-1}$ Raman peak and the broadening of other Raman peaks (spectrum II, Figure 2a), revealing nanocrystalline features. The $v$ band at $\sim 1140 \mathrm{~cm}^{-1}$ originates from the $\mathrm{C}=\mathrm{C}$ and $\mathrm{C}-\mathrm{H}$ bonds of the trans-polyacetylene phases. These trans- 
polyacetylene phases are existing at the film's grain boundaries. ${ }^{43}$ The $s p^{3}$-peak $\left(1334 \mathrm{~cm}^{-1}\right)$ clearly decreases as $\mathrm{CH}_{4}$-content increases, corresponding to a grain size reduction and increase of grain boundaries. A further increase of the percentage of $\mathrm{CH}_{4}$ used (10\% or $\left.15 \%\right)$, renders the diamondrelated peak at $1334 \mathrm{~cm}^{-1}$ barely observable (spectra III and IV, Figure 2a, respectively). All peaks become considerably broadened. Particularly, the peaks in the $1400-1600 \mathrm{~cm}^{-1}$ region become evident, ${ }^{44,45}$ which indicates a huge amount of $s p^{2}$-bonderd carbon is occurred in these materials. The nanographite formation in NDNN films is indicated by the presence of a broad 2D band around $2709 \mathrm{~cm}^{-1} .^{46}$ Although the Raman spectra distinctly change with the change in $\mathrm{CH}_{4}$ concentration, which is further reflected by the $\mathrm{I}_{\mathrm{dia}} / \mathrm{I}_{\mathrm{G}}$ intensity expressing the $s p^{3}$ - to $s p^{2}$-bonded carbon ratio in the films, one needs to take into account that Raman spectroscopy with an excitation wavelength $\lambda=488 \mathrm{~nm}$ is sensitive to the $s p^{2}$-bonded carbon materials. ${ }^{47}$ Hence, a supplementary EELS study using TEM was done to compliment this analysis, which will be discussed shortly.

The four-point probe technique was employed to measure the electrical resistivity of the films. The $\mathrm{NCD}_{1}$ films have a resistivity value of $150 \times 10^{6} \Omega \cdot \mathrm{cm}$. The resistivity values follow a downward trend with increased $\mathrm{CH}_{4}$ concentration, to reach the lowest resistivity of $90 \Omega \cdot \mathrm{cm}$ for the NDNN films. Figure 3a displays the FEE plots of current density $(J)$ versus applied field $(E)$ curves. The inset of Figure 3a shows the Fowler Nordheim (FN) plots corresponding to the $J-E$ curves shown in Figure 3a. The turn-on field $\left(E_{0}\right)$ and $J$ values were estimated from the obtained $I$ - $V$ curves using the FN equation. ${ }^{48}$ The $E_{0}$ value is estimated from the point of interception of the straight lines inferred from high-field and low-field portions of the FN plots, viz. $\ln \left(J / E^{2}\right)-1 / E$ curves. The FEE process based on the $\mathrm{NCD}_{1}$ films requires a very large field (44.0 V/ $\left.\mu \mathrm{m}\right)$ (curve I, Figure 3a) to turn on and eventually only reaches a very small $J$ of $\sim 0.08 \mathrm{~mA} / \mathrm{cm}^{2}$ at $E=68.1$ $\mathrm{V} / \mu \mathrm{m}$. With the increase of $\mathrm{CH}_{4}$ concentration the $E_{0}$ value decreases monotonously (curve I, 
Figure $3 \mathrm{~b}$ ) and the $J$ shows reverse trend, i.e., $J$ increases monotonously with $\mathrm{CH}_{4}$ concentration, so that the NDNN films show the best FEE behavior among the four types of samples studied, i.e. a low $E_{0}$ of $4.3 \mathrm{~V} / \mu \mathrm{m}$ and a high $J$ of $3.3 \mathrm{~mA} / \mathrm{cm}^{2}$ at $E=8.6 \mathrm{~V} / \mu \mathrm{m}$ (curve IV, Figure 3a). Furthermore the slope $(m)$ of the FN plot via the equation: $\beta=\left[-6.8 \times 10^{3} \varphi^{3 / 2}\right] / m$ provides the field enhancement factor ( $\beta$ ), where $\varphi$ is the work function of the material. Using the $\varphi$ value as $5.0 \mathrm{eV}$ for diamond, ${ }^{49}$ the $\beta$ values of the NCD films were calculated from the FN plots. The $\mathrm{NCD}_{1}$ films exhibit the smallest $\beta$ value of 410 (curve II, Figure 2b). Concurring with the observed FEE behavior, the $\beta$ value increases consistently with the increase in $\mathrm{CH}_{4}$ concentration, so that the NDNN films possess a $\beta$ value that is almost 9 times as large as of the $\mathrm{NCD}_{1}$ film. The $\beta$ value of 3865 for NDNN films is prominently attributed to the 1D nanoneedle structured diamond grains present in these films. The variation in the FEE characteristics is plotted in Figure $3 \mathrm{~b}$ and also tabulated in Table 1. It can be clearly noticed that lower the resistivity of the films better the FEE properties comparable to those of the conducting diamond films reported. ${ }^{30,50-55}$

A more interesting phenomenon is that the PI characteristics of the microplasma device is improved by employing NDNN films as a cathode. The panels of photographs shown in Figure 4a display the PI characteristics of the plasma devices operating with the $\mathrm{NCD}_{z}$ films as cathode materials. Panel IV in Figure 4a shows that the NDNN films as cathode in the microplasma device ignited the plasma at the lowest voltage $(360 \mathrm{~V})$ as compared to other NCD films as cathodes (panels I, II and III in Figure 4a respectively). The brightness of the PI photographs increases with the applied voltage. Figure $4 \mathrm{~b}$ illustrates the plasma current density $\left(J_{\mathrm{PI}}\right)$ versus applied field $(E)$ curves. A systematic variation in the threshold field $\left(E_{\mathrm{th}}\right)$ is observed when increasing the increase of $\mathrm{CH}_{4}$ concentration (Table 1) and the NDNN films show the low $E_{\text {th }}$ value of $3600 \mathrm{~V} / \mathrm{cm}$. The change in $E_{\text {th }}$ values is similar to the change in $E_{0}$ values in the FEE behavior of these NCD films 
(cf. Figure 3). Moreover, the NDNN films show the largest $J_{\mathrm{PI}}$ value of $1.14 \mathrm{~mA} / \mathrm{cm}^{2}$ at $\mathrm{E}=5000$ V/cm. These observations specify that the cathode material possessing superior FEE properties perform better in the microplasma devices. In addition, to estimate the stability of the NDNN films, the $J_{\mathrm{PI}}$ of $1.14 \mathrm{~mA} / \mathrm{cm}^{2}$ is examined at an applied voltage of $500 \mathrm{~V}$. It is observed that the NDNN films possess a high lifetime stability of 881 min (inset of Figure 4b) when utilizing the films as cathodes in the microplasma devices.

Seemingly, the enhanced FEE and PI characteristics of NDNN films are associated to the microstructure of the films. To know the origin of these nanoneedles in NDNN films and the associated FEE and PI characteristics, the microstructure of these films due to the change in $\mathrm{CH}_{4}$ concentration was investigated using TEM. Figure 5a, 6a, 7a and 8a show the bright field (BF) low-magnification TEM micrographs of the films grown at 1, 5, 10 and $15 \% \mathrm{CH}_{4}$ concentration, respectively. The insets of Figure 5a, 6a, 7a and 8a display the corresponding selective-area electron diffraction (SAED) patterns of these micrographs. Figure 5a depicts the microstructure of $\mathrm{NCD}_{1}$ films, indicating that the grains are very large $(\sim 600 \mathrm{~nm})$. It is to be noted that the grains displays high contrast because they are oriented near to some zone-axis and hence diffract electrons strongly. The SAED pattern displayed in the inset of Figure 5a shows only discrete diffraction spots rather than continuous diffraction rings, which represents that the size of the diamond grains contributing to the diffraction spots are large. These discrete spot patterns are organized as a ring, inferring the random orientation of the diamond grains. Besides, a very sharp negligible thickness of the grain boundaries are observed. Such a granular structure is same with the observations for typical NCD films. ${ }^{56}$ The merged dark field TEM (m-DF-TEM) images of NCD ${ }_{1}$ films shown in Figure 5b were attained from different diffraction spots of the SAED pattern (inset, Figure 5b), and were then superimposed. Figure 5b displays the m-DF-TEM micrograph representing to the 
marked region " $\mathrm{A}_{1}$ " in Figure 5a discloses that the region next to the yellow colored grain corresponds to blue colored diamond grain that aligned in different orientation. A sharp and precise boundaries are observed between these diamond grains. Furthermore, Figure 5c, the high resolution TEM (HRTEM) micrograph of $\mathrm{NCD}_{1}$ films, clarifies the detailed microstructure of region " $\mathrm{A}_{2}$ " in the $\mathrm{NCD}_{1}$ films and reveals a complicated microstructure in the diamond grain. Furthermore, the $\mathrm{NCD}_{1}$ film mainly consists of [011] zone axis oriented cubic diamond phase, which is revealed from the Fourier transformed (FT) diffractogram image $\left(\mathrm{FT}_{0 \mathrm{~A}}\right)$ representing to the complete structure image. The planar defects, possibly stacking faults, are also present in the $\mathrm{NCD}_{1}$ film, which are exposed by the $\mathrm{ft}_{\mathrm{a} 1}-\mathrm{ft}_{\mathrm{a}}$ images corresponding to the "a1-a3" regions, respectively. ${ }^{57}$

Increase in $\mathrm{CH}_{4}$ concentration to $5 \%$ distinctly changes the microstructure of the NCD films. The BF-TEM image of the $\mathrm{NCD}_{5}$ films shown in Figure 6a illustrates that besides the presence of large diamond grains ( $\sim 100-200 \mathrm{~nm})$ in the $\mathrm{NCD}_{5}$ films, small diamond clusters of size $<20 \mathrm{~nm}$ are also existed. Such a microstructure is more evidently demonstrated in the m-DF-TEM micrograph corresponding to region " $\mathrm{B}_{1}$ " (Figure 6b). The yellow colored features in Figure $6 \mathrm{~b}$ agreeing to the yellow spot in the (111) ring of the SAED pattern (inset, Figure 6b) represent the presence of nano- as well as micron-sized diamond grains. On the other hand, the green colored features in Figure 6b agreeing to the green spot in the SAED pattern (inset, Figure 6b) disclose the existence of graphitic phases in the $\mathrm{NCD}_{5}$ films. Remarkably, the appearance of extra diffraction spots as a ring pattern relates to $n$-diamond $(n-D ; 200)$ phases, specified by an arrow in the inset of Figure 6a. Notably, $n-D$ is a diamond allotrope with a cell parameter of $0.356 \mathrm{~nm}$ and a space group symmetry of Fm3m. ${ }^{58,59}$ A detailed HRTEM investigations were accomplished to recognize the distinct phase constituents in the $\mathrm{NCD}_{5}$ films. Figure 6c displays the HRTEM image of the 
$\mathrm{NCD}_{5}$ films agreeing to region " $\mathrm{B}_{2}$ " in Figure $6 \mathrm{a}$. The $\mathrm{FT}_{0 \mathrm{~B}}$ image containing a spotted diffraction pattern represents the presence of diamond (D) grains. The $s p^{2}$-carbon phase ( $a$ - $C$ or graphite) is represented by a diffused diffraction ring at the center of the $\mathrm{FT}_{0 \mathrm{~B}}$ image. In addition, diffraction spots found nearer to the (111) diamond ring are visible, displaying the existence of $n$ - $D$ clusters. The FT, $\mathrm{ft}_{\mathrm{b} 1}$, $\mathrm{ft}_{\mathrm{b} 2}$, and $\mathrm{ft}_{\mathrm{b} 3}$, images corresponding to "b1", "b2" and "b3" regions in Figure 6c, highlight the diamond (D), graphite (G) and $n-D$ phases, respectively. The graphite and $a$ - $C$ phases show a central diffuse ring of donut geometry, and full-moon geometry in FT images, respectively, unlike the $\mathrm{FT}_{0 \mathrm{~B}}$ image, implying that the $\mathrm{NCD}_{5}$ films contain a mixture of crystalline and amorphous phase $s p^{2}$-carbons.

Figure 7a illustrates the BF-TEM image of NCD10 films representing that the films contains clusters of uniformly distributed spherical particulates of size around tens of nanometers. The existence of clear boundaries in these spherical particulates and the strong diffraction rings representing to the (311), (220) and (111) lattices of diamond in the SAED patterns (inset of Figure 7a) confirms that this material is effectively diamond. Unlike the observations in the SAED of the $\mathrm{NCD}_{5}$ films (inset, Figure 6a), besides the diamond ring no extra diffraction ring is detected for the $\mathrm{NCD}_{10}$ films (inset, Figure 7a). This means that the formation of $n-D$ clusters is effectively suppressed due to the addition of more $\mathrm{CH}_{4}$ in the plasma.

The microstructure of $\mathrm{NCD}_{10}$ is also evidently noticeable from its m-DF TEM images (Figure 7b) representing to region " $\mathrm{C}_{1}$ " in Figure 7a. The yellow colored features attained from the yellow spots in the SAED pattern represent the presence of diamond phase and the green colored features from the green spots (inset of Figure 7b) indicates the $s p^{2}$ bonded graphitic phases. The HRTEM image of the typical regions in these films (marked region " $\mathrm{C}_{2}$ " of Figure $7 \mathrm{a}$ ) is revealed in Figure 7c. The ring shaped spotted diffraction pattern in $\mathrm{FT}_{0 \mathrm{C}}$ image displays the diamond (D) phase and 
the diffused ring at the center of the $\mathrm{FT}_{0 \mathrm{C}}$ image characterizes the $s p^{2}$-bonded carbon phase. Furthermore, the $\mathrm{ft}_{\text {-images, }} \mathrm{ft}_{\mathrm{c} 1}, \mathrm{ft}_{\mathrm{c} 1}$, and $\mathrm{ft}_{\mathrm{c} 3}$, emphasize the diamond (region "c1") and graphitic phases (regions “c2” and “c3”), respectively. Again, the $\mathrm{FT}_{0 \mathrm{C}}$ image illustrates that a partially of full-moon shaped and a partially of donut shaped central diffuse ring indicates the co-existence of $a-C$ and graphitic phases.

It is intriguing to notice that for the films synthesized with $\mathrm{CH}_{4}=15 \%$, the microstructure of the diamond materials changes dramatically. The diamond grains evolved into a nanoneedle geometry, rather than an equal-axed one. A BF-TEM micrograph of the NDNN films illustrated in Figure 8a indicates the origin of nanostructures with the branching features indicating an anisotropic grain growth. Figure 8b displays the m-DF-TEM micrographs of the NDNN films representing to region " $\mathrm{D}_{1}$ " in Figure 8a, revealing clearly the evolution of spherical shaped diamond grain (yellow color) into needle-like ones with green featured graphitic phases surrounding it. The HRTEM micrograph displayed in Figure 8c, representing to the region " $\mathrm{D}_{2}$ " in Figure 8a, brings out a core-shell microstructure in the NDNN films. The graphitic layers of thickness ranging from a few atomic layers to more than 10 layers are encasing the diamond grains. This kind of microstructure was noticed on UNCD films by many groups. ${ }^{31,34,35,40}$ In addition to the diffraction spots of diamond grains, the $\mathrm{FT}_{0 \mathrm{D}}$ image shows a thick donut-shaped central diffuse ring representing the graphite phase. Additionally, the $\mathrm{ft}_{\mathrm{d} 1}$, $\mathrm{ft}_{\mathrm{d} 2}$, and $\mathrm{ft}_{\mathrm{d} 3}$ images authorize the presence of diamond in region "d1" and graphite in regions “d2" and "d3", respectively.

The linear diffraction patterns (ldp) shown in Figure 2b are used to clarify the different phase constituents in these films. These ldp patterns were acquired from the SAED images (insets of Figure 5a, 6a, 7a, and 8a). Spectrum I of Figure 2b, where the corresponding Miller indexes of the diamond lattice planes are designated, reveals that the $\mathrm{NCD}_{1}$ films comprise only diamond. 
Increase of $\mathrm{CH}_{4}$ concentration to $5 \%$ induces the formation of $n-D$ phases in $\mathrm{NCD}_{5}$ films (designated as “ $n-D$ ” in spectrum II of Figure 2b), where the coexistence of ultra-small diamond particulates with larger diamond grains can only be revealed by TEM micrographs (cf. Figure 6a). The ldp spectrum does not change when more $\mathrm{CH}_{4}$ was added in the $\mathrm{CH}_{4} / \mathrm{H}_{2} / \mathrm{N}_{2}$ plasma, but the BF-TEM micrographs in Figure 6a and 7a indicate that there is an increase in the quantity of nanodiamond particulates when the $\mathrm{CH}_{4}$-content increased. The $\mathrm{NCD}_{10}$ films contain uniform nanodiamond particulates (spectrum III of Figure 2b). Again increase in $\mathrm{CH}_{4}$-content to $15 \%$ ensued in the origin of nanoneedle structure (cf. Figure 8a) along with abundant graphitic phases, as clearly evidenced in spectrum IV of Figure 2b, which are consistent with the BF-TEM and m-DF-TEM analyses.

The analyses of diamond materials are rather difficult as there are many allotropes for diamond, and even more different phases for carbon materials. Some of the phases cannot be clearly identified in SAED diffraction analyses, therefore the NCD films' phase constituents are further analyzed using selective area EELS spectra. The core-loss and plasmon-loss EELS spectra, agreeing to the BF-TEM images of Figure 5a, 6a, 7a, and 8a, shown in Figure 2c and 2d clearly clarify an evolution in the bonding structures of the $\mathrm{NCD}_{\mathrm{z}}$ films attributed to the concentration of $\mathrm{CH}_{4}$ in the $\mathrm{CH}_{4} / \mathrm{H}_{2} / \mathrm{N}_{2}$ plasmas. Figure 2c illustrates the carbon edge core-loss EELS spectra of all $\mathrm{NCD}_{z}$ films displaying a quick increase around $289.0 \mathrm{eV}$ ( $\sigma^{*}$-band) and a large dip at $302.0 \mathrm{eV}$, confirming the diamond nature of these films. ${ }^{60,61}$ Moreover, spectrum III of Figure 2c shows a very small $\pi^{*}$-band at $285.0 \mathrm{eV}$ confirming that the $s p^{2}$-bonded carbon is formed in the $\mathrm{NCD}_{10}$ films. But the $s p^{2}$-bonded carbon is insignificant in the spectra I and II of Figure 2c for $\mathrm{NCD}_{1}$ and $\mathrm{NCD}_{5}$ films, respectively. Notably, the $\pi^{*}$-band intensity in spectrum IV of Figure 2c is markedly 
larger as compared to spectrum III, concluding that the NDNN films contain more graphitic phases than the $\mathrm{NCD}_{10}$ films.

Though the core-loss EELS spectrum reveals the basic features of $s p^{2}$-bonded and $s p^{3}$-bonded carbons, particularly the graphite and the $a-C$ phases are explicitly distinguished by plasmon-loss EELS spectrum. In the plasmon-loss EELS spectrum, the diamond phase is represented by the peaks at $23 \mathrm{eV}$ ( $\mathrm{S}_{2}$-band; surface plasmons) and $33 \mathrm{eV}$ ( $\mathrm{S}_{4}$-band; bulk plasmons), whereas the $a-C$ and graphite phases are signified by the peaks near $22 \mathrm{eV}$ ( $\mathrm{S}_{1}$-band) and $27 \mathrm{eV}$ ( $\mathrm{S}_{3}$-band), respectively. ${ }^{60,61}$ Figure 2d represents the plasmon-loss EELS spectra of NCDz fims, where these spectra were attained from the same regions where the core-loss EELS spectra were acquired. Spectra I and II of Figure 2d are dominated by bulk plasmon and surface plasmon losses, designating that $\mathrm{NCD}_{1}$ and $\mathrm{NCD}_{5}$ films are dominated mainly by diamond. The plasmon-loss spectrum of $\mathrm{NCD}_{10}$ films (spectrum III, Figure 2d) shows a predominant $\mathrm{S}_{4}$-band around $33 \mathrm{eV}$ and a significant shoulder $\mathrm{S}_{2}$-band at $23 \mathrm{eV}$ those representing diamond and the $\mathrm{S}_{1}$-band confirms the existence of $a-C$ in the $\mathrm{NCD}_{10}$ films. In contrary, the plasmon-loss spectrum for the NDNN films shown as spectrum IV in Figure 2d reveals less intensity of $\mathrm{S}_{2}$ - and $\mathrm{S}_{4}$-bands but a dominant $\mathrm{S}_{3}$-band at $27 \mathrm{eV}$ represents the presence of nanographitic phases in NDNN films rather than $a-C$. Hence, it is evident that the EELS analyses are mandatory in order to unambiguously analyze the TEM microstructure of the materials.

The above-depicted results evidently clarified the impact of $\mathrm{CH}_{4}$ in $\mathrm{CH}_{4} / \mathrm{H}_{2} / \mathrm{N}_{2}$ plasmas on modifying the morphology, microstructure, and bonding characteristics of NCD films grown using the MWPECVD system. The TEM and Raman studies have demonstrated that the evolution of nanoneedles with diamond-graphite core-shell structure (cf. m-DF-TEM micrograph of Figure 8) leads to the improved electrical conductivity as well as the enhanced FEE properties of the NDNN 
films. These core-shell structures of NDNN films possess high aspect ratio that can transport the electrons without any difficulty to the emitting surface and then emit the electrons to vacuum effectively. Subsequently, the NDNN films own the best FEE characteristics among the NCD films (cf. Figure 3 and Table 1).

However, the problem to be explained is what is/are the critical aspect/s acting behind the origin of nanoneedle in NDNN films? To make the growth mechanism the plasma constituents were recorded using in situ OES measurements (Figure 9). $\mathrm{H}_{\alpha}$ at 655.3 and $\mathrm{H}_{\beta}$ at $486.0 \mathrm{~nm}$ are the prominent Balmer atomic hydrogen emission lines, which are detected for the $1 \% \mathrm{CH}_{4}$ containing plasma (spectrum I, Figure 9a). ${ }^{62,63} \mathrm{~N}_{2}$ peak at $357.3 \mathrm{~nm}$ and the $\mathrm{CN}$ violet system at $387.3 \mathrm{~nm}$ and $418.1 \mathrm{~nm}$ were observed because of the incorporation of nitrogen. ${ }^{64}$ Because of the dissociation of $\mathrm{CH}_{4}$ species, there is presence of $\mathrm{CH}$ species, however the $\mathrm{CH}$ band was totally overlapped by the CN band ${ }^{65}$ Hence, we marked the peaks at $387.3 \mathrm{~nm}$ and $418.1 \mathrm{~nm}$ as $\mathrm{CN}+\mathrm{CH}$. Moreover, there is a minimal amount of $\mathrm{C}_{2}$ species in spectrum $\mathrm{I}$, which is considered to be the key species renucleating in the synthesis of ultra-small diamond grains of UNCD films. Moreover, it is acknowledged that the $\mathrm{CH}_{3}$ species in $\mathrm{CH}_{4} / \mathrm{H}_{2}$ plasma (without addition $\mathrm{N}_{2}$ ) are the main species responsible for the synthesis of micron-sized diamond grains in the MCD films. ${ }^{25,26} \mathrm{But} \mathrm{CH}_{3}$ species, responsible for the diamond growth, is not noticeable in this OES spectrum. ${ }^{66}$ The $\mathrm{NCD}_{1}$ films seem to grow by the same mechanism as MCD films, but the grain size is significantly small because of the existence of $(\mathrm{CN}+\mathrm{CH})$ species in the plasma. $\mathrm{CN}$ species seem not playing any role in the micron-sized grain formation because a low substrate temperature of $540{ }^{\circ} \mathrm{C}$ is required to synthesize the $\mathrm{NCD}_{1}$ films (cf. curve I of Figure 1e), while CN requires a high activation energy in the plasma, which is only achieved at plasma conditions that would lead to high substrate temperatures of about $700{ }^{\circ} \mathrm{C} \cdot{ }^{32-34}$ 
While the concentration of $\mathrm{CH}_{4}$ increases in $\mathrm{CH}_{4} / \mathrm{H}_{2} / \mathrm{N}_{2}$ plasma, the $\mathrm{C}_{2}$ swan system ( 472 $\mathrm{nm}$ and $\sim 516 \mathrm{~nm}$ ) starts to be present and its percentage starts rise with the $\mathrm{CH}_{4}$-content in the plasma. ${ }^{65}$ This is more visible in Figure $9 \mathrm{~b}$ in spectra with an enlarged scale in the $460-540 \mathrm{~nm}$ regime. It is reported that $\mathrm{CH}$ and $\mathrm{C}_{2}$ species are dominating the UNCD film's growth in a plasma containing $\mathrm{CH}_{4}$ and Ar gas mixtures, ${ }^{27,28,67}$ the $\mathrm{C}_{2}$-species re-nucleate diamond easily, whereas the $\mathrm{CH}$ species passivate the diamond nuclei and efficiently ensuing in equi-axed ultra-small diamond grains. ${ }^{28}$ Presumably, a similar mechanism is happening for the modification of micron-sized diamond grains to nano-sized diamond grains while changing the $\mathrm{CH}_{4}$ concentration from 1 to $10 \%$, that is, once the nano-sized diamond grains form, the $\mathrm{CH}$-species stick to these diamond grains and create a hydrocarbon layer ( $t$-PA; Raman spectra II and III of Figure 2a) surrounding these diamond grains. ${ }^{43}$ This makes the active $\mathrm{C}_{2}$ species in the plasma are not able to create a direct contact with the diamond surface. As a result, the new $\mathrm{C}_{2}$ species renucleate to form new diamond clusters, instead of enlarging the size of the present diamond clusters by attaching to their surface. Hence, the $\mathrm{CH}$ and $\mathrm{C}_{2}$ species assist in the formation of nano-sized grains of diamond in $\mathrm{NCD}_{5}$ and $\mathrm{NCD}_{10}$ films. Moreover, the $5 \% \mathrm{CH}_{4}$-containing plasma not only contains less $\mathrm{C}_{2}$ and $(\mathrm{CN}+\mathrm{CH})$ species, but also leads to a much lower substrate temperature $\left(650^{\circ} \mathrm{C}\right)$ compared with the $10 \% \mathrm{CH}_{4}$-containing plasma yielding a substrate temperature of $710{ }^{\circ} \mathrm{C}$. Therefore, it is difficult to form diamond crystals in 5\% $\mathrm{CH}_{4}$-containing plasma such that imperfect diamond (e.g. $n-D$ particulates) were observed in $\mathrm{NCD}_{5}$ films but not in $\mathrm{NCD}_{10}$ films. However, the genuine growth mechanism for the formation of $n-D$ particulates entailed more systematic investigation.

Theoretical studies revealed that the definite faces (for example (100) faces) of the nanodiamond clusters are preferentially attached by the CN species and encourage the formation of diamond nanoneedles. ${ }^{68}$ The $\mathrm{CN}$ species are adhered on the surface of the $\mathrm{C}_{2}$ dimers that result in 
an anisotropic diamond growth in [100] direction, in which the energetically favorable CN molecule stays on the growth surface. ${ }^{68-70}$ Moreover, previous studies ${ }^{34-36}$ observed that above $700^{\circ} \mathrm{C}$, the equi-axed like granular structure changes to needle-like structure because of the occurrence of large quantity of CN species. Together with the above-defined results, it is proven that the CN species are significant for the origin of nanoneedles for the NDNN films. However, a high substrate temperature is necessary for triggering the $\mathrm{CN}$ species in inducing the attachment of $\mathrm{C}_{2}$ species through the $\mathrm{CN}$ adhered surface. For $10 \% \mathrm{CH}_{4}$-containing plasmas, the substrate temperature is $710^{\circ} \mathrm{C}$, which is barely sufficient for the anisotropic attachment of $\mathrm{C}_{2}$ species along (100) direction. Whereas for $15 \% \mathrm{CH}_{4}$-containing plasmas, the substrate temperature is $780^{\circ} \mathrm{C}$ and hence $\mathrm{CN}$ species are dominant than $\mathrm{CH}$ species that leading to preferential attachment of $\mathrm{C}_{2}$ species and inducing the anisotropic growth of diamond grains. Therefore, in NDNN films the smaller grains start to combine along any desired direction, ensuing in high aspect ratio diamond nanoneedles. Moreover, during the anisotropic growth, the surface $\mathrm{C}$ atoms surrounding the $s p^{3}$ bonded diamond core tend to form $s p^{2}$-bonded carbon as it is energetic favorable. That is, it is a natural tendency on the formation of graphitic layers surrounding the anisotropic growth of diamond grains. Hence, the core-shell microstructure of diamond and graphite facilitate the electron transport via the graphitic phases to the emitting film surface, rendering NDNN films to show enhanced FEE characteristics.

\section{- CONCLUSIONS}

We scientifically investigated the change in microstructure of nanocrystalline diamond films by varying the $\mathrm{CH}_{4}$ percentage in $\mathrm{CH}_{4} / \mathrm{H}_{2} / \mathrm{N}_{2}$ (3\%) plasma. The studies based on SEM, Raman spectroscopy and TEM were examined to understand the evolutions in the morphology, bonding structure and microstructure of these films. It is found that, while the $\mathrm{CH}_{4}$ concentration at $1 \%$ 
resulted in faceted-type diamond grains, increasing the $\mathrm{CH}_{4}$ concentration into the plasma decreased monotonously the size of the grains, ensuing in nano-sized diamond grains for $10 \%$ $\mathrm{CH}_{4}$-concentrated NCD films. Interestingly, when the $\mathrm{CH}_{4}$-content increases to $15 \%$ enables the origin of nanocrystalline diamond nanoneedles encased in nanographitic phases, i.e. core-shell granular structured films. This granular structure proved to be most promising for FEE applications, as the graphitic shells provide a conducting pathway transporting the charge carriers to the surface of the NCD film. A low resistivity and superior FEE and PI characteristics were achieved for these nanocrystalline diamond nanoneedles films. The OES investigation showed that the occurrence of $\mathrm{C}_{2}$ and $\mathrm{CN}$ species with larger proportion at higher $\mathrm{CH}_{4}$-content in the plasma is the key factor for the observed microstructural changes of the nanocrystalline diamond films. More importantly, the substrate temperature is increased to $780^{\circ} \mathrm{C}$ for the $15 \% \mathrm{CH}_{4}$-containing $\mathrm{CH}_{4} / \mathrm{H}_{2} / \mathrm{N}_{2}$ plasma. This temperature is sufficient for triggering the anisotropic growth of diamond grains and forms nanocrystalline diamond nanoneedles. These combined observations reveal that the optoelectronic characteristics of the nanocrystalline diamond materials can be optimized, which opening up pathways for the advanced optoelectronic device applications.

\section{- AUTHOR INFORMATION}

\section{Corresponding Author}

*E-mail: sankaran.kamatchi@uhasselt.be; ken.haenen@uhasselt.be

\section{Notes}

The authors declare no competing financial interest.

\section{- ACKNOWLEDGEMENTS}

The authors like to thank the financial support of the Research Foundation Flanders (FWO) via Research Grant 1519817N, and the Methusalem "NANO” network. The Hercules Foundation 
Flanders is acknowledged for financial support of the Raman equipment. Kamatchi Jothiramalingam Sankaran and Paulius Pobedinskas are Postdoctoral Fellows of the Research Foundation-Flanders (FWO).

\section{REFERENCES}

(1) Yang, T. H.; Chiu, K. C.; Harn, Y. W.; Chen, H. Y.; Cai, R. F.; Shyue, J. J.; Lo, S. C.; Wu, J. M.; Lee, Y. H. Electron Field Emission of Geometrically Modulated Monolayer Semiconductors. Adv. Funct. Mater. 2018, 28, 1706113.

(2) Cole, M. T.; Parmee, R. J.; Milne, W. I. Nanomaterial-based X-ray Sources. Nanotechnology 2016, 27, 082501.

(3) Sankaran, K. J.; Ficek, M.; Kunuku, S.; Panda, K.; Yeh, C. J.; Park, J. Y.; Sawczak, M.; Michałowski, P. P.; Leou, K. C.; Bogdanowicz, R.; Lin, I. N.; Haenen, K. Self-organized Multilayered Graphene-Boron Doped Diamond Hybrid Nanowalls for High Performance Electron Emission Devices. Nanoscale 2018, 10, 1345-1355.

(4) Yousefi, A. T.; Tanaka, H.; Bagheri, S.; Elfghi, F.; Mahmood, M. R.; Ikeda, S. Vectorial Crystal Growth of Oriented Vertically Aligned Carbon Nanotubes Using Statistical Analysis. Cryst. Growth Des. 2015, 15, 3457-3463.

(5) Chen, L.; Yu, H.; Zhong, J.; Song, L.; Wu, J.; Su, W. Graphene Field Emitters: A Review of Fabrication, Characterization and Properties. Mater. Sci. Engg. B 2017, 220, 44-58.

(6) Liu, D.; Benstetter, G.; Frammelsberger, W. Nanoscale Electron Field Emission from the Bare, Hydrogenated, and Graphite like-layer-covered Tetrahedral Amorphous Carbon Films. J. Appl. Phys. 2006, 99, 044303. 
(7) Zanin, H.; May, P. W.l Hamanaka, M. H. M. O.; Corat, E. J. Field Emission from Hybrid Diamond-like Carbon and Carbon Nanotube Composite Structures. ACS Appl. Mater. Interfaces. 2013, 5, 12238-12243.

(8) Terranova, M. L.; Orlanducci, S.; Rossi, M.; Tamburri, E. Nanodiamonds for Field Emission: State of the Art. Nanoscale 2015, 7, 5094-5114.

(9) Saravanan, A.; Huang, B.R.; Manoharan, D.; Lin, I. N. High-performance Electron Field Emitters and Microplasma Cathodes Based on Conductive Hybrid Granular Structured Diamond Materials. ACS Appl. Mater. Interfaces 2017, 9, 4916-4925.

(10) Mendoza, F.; Makarov, V.; Weiner, B. R.; Morell, G. Solar-blind Field-emission Diamond Ultraviolet Detector. Appl. Phys. Lett. 2015, 107, 201605.

(11) Sankaran, K. J.; Joseph, P. T.; Chen, H. C.; Tai, N. H.; Lin, I. N. Investigation in the Role of Hydrogen on the Properties of Diamond Films Grown using $\mathrm{Ar} / \mathrm{H}_{2} / \mathrm{CH}_{4}$ Microwave Plasma. Diamond Relat. Mater. 2011, 20, 232-237.

(12) Schoenbach, K. H.; Becker, K. 20 years of Microplasma Research: A Status Report. Eur. Phys. J. D 2016, 70, 29.

(13) Barekzi, N.; Laroussi, M. Effects of Low Temperature on Cancer Cells. Plasma Processes Polym. 2013, 10, 1039-1050.

(14) Sankaran, K. J.; Huang, B. R.; Saravanan, A.; Manoharan, D.; Tai, N. H.; Lin, I. N. Heterogranular-Structured Diamond-Gold Nanohybrids: A New Long-Life Electronic Display Cathode. ACS Appl. Mater. Interfaces 2015, 7, 27078-27086.

(15) Palomino, J.; Varshney, D.; Resto, O.; Weiner, B. R.; Morell, G. Ultrananocrystalline Diamond-Decorated Silicon Nanowire Field Emitters. ACS Appl. Mater. Interfaces, 2014, 6, 13815-13822. 
(16) Pandey, A.; Prasad, A.; Moscatello, J.; Yap, Y. K. Stable Electron Field Emission from PMMA-CNT Matrices. ACS Nano 2010, 4, 6760-6766.

(17) Chang, T. H.; Kunuku, S.; Hong, Y. J.; Leou, K. C.; Yew, T. R.; Tai, N. H.; Lin, I. N. Enhancement of the Stability of Electron Field Emission Behavior and the Related Microplasma Devices of Carbon Nanotubes by Coating Diamond Films. ACS Appl. Mater. Interfaces 2014, 6, 11589-11597.

(18) Chang, T. H.; Hsieh, P. Y.; Kunuku, S.; Lou, S. C.; Manoharan, D.; Leou, K. C.; Lin, I. N.; Tai, N. H. High Stability Electron Field Emitters Synthesized via the Combination of Carbon Nanotubes and N2-Plasma Grown Ultrananocrystalline Diamond Films. ACS Appl. Mater. Interfaces 2015, 7, 27526-27538.

(19) Venkattraman, A. Theory and Analysis of Operating Modes in Microplasms Assisted by Field Emitting Cathodes. Phys. Plasmas 2015, 22, 057102.

(20) Chen, W. E.; Chen, C.; Yeh, C. J.; Hu, X.; Leou, K. C.; Lin, I. N. Evolution of Granular Structure and the Enhancement of Electron Field Emission Properties of Nanocrystalline and Ultrananocrystalline Diamond Films Due to Plasma Treatment Process. ACS Appl. Mater. Interfaces 2018, 10, 28726-28735.

(21) Wang, C. S.; Chen, H. C.; Cheng, H. F.; Lin, I. N. Origin of Platelike Granular Structure for the Ultrananocrystalline Diamond Films Synthesized in H2-containing Ar/CH4 Plasma. J. Appl. Phys. 2010, 107, 034304.

(22) Krauss, A. R.; Auciello, O.; Gruen, D. M.; Jayatissa, A.; Sumant, A.; Tucek, J.; Mancini, D. C.; Moldovan, N.; Erdemir, A.; Ersoy, D.; Gardos, M. N.; Busmann, H. G.; Meyer, E. M.; Ding, M. Q. Ultrananocrystalline Diamond Thin Films for MEMS and Moving Mechanical Assembly Devices. Diamond Relat. Mater. 2001, 10, 1952-1961. 
(23) Mohr, M.; Daccache, L.; Horvat, S.; Brühne, K.; Jacob, T.; Fecht, H. J. Influence of Grain Boundaries on Elasticity and Thermal Conductivity of Nanocrystalline diamond films. Acta Materialia. 2017, 122, 92-98.

(24) Zhou, D.; McCauley, T. G.; Qin, L. C.; Krauss, A. R.; Gruen, D. M. Synthesis of Nanocrystalline Diamond Thin Films from an Ar-CH4 Microwave Plasma. J. Appl. Phys. 1998, 83, 540-543.

(25) Celii, F. G.; Pehrsson, P. E.; Wang, H. T.; Butler, J. E. Infrared Detection of Gaseous Species During the Filament-Assisted Growth of Diamond. Appl. Phys. Lett. 1988, 52, 2043-2045.

(26) Childs, M. A.; Menningen, K. L.; Chevako, P.; Spellmeyer, N. W.; Anderson, L. W.; Lawler, J. E. Detection of CH3 During CVD Growth of Diamond by Optical Absorption. Phys. Lett. A 1992, 171, 87-89.

(27) Gicquel, A.; Hassouni, K.; Farhat, S.; Breton, Y.; Scott, C. D.; Lefebvre, M.; Pealat, M. Spectroscopic Analysis and Chemical Kinetics Modeling of a Diamond Deposition Plasma Reactor. Diamond Relat. Mater. 1994, 3, 581-586.

(28) Eckert, M.; Neyts, E.; Bogaerts, A. Insights into the Growth of (Ultra)nanocrystalline Diamond by Combined Molecular Dynamics and Monte Carlo Simulations. Crys. Growth Des. 2010, 10, 3005-3021.

(29) Corrigan, T. D.; Gruen, D. M.; Krauss, A. R.; Zapol, P.; Chang, R. P. H. The Effect of Nitrogen Addition to Ar/CH4 Plasmas on the Growth, Morphology and Field Emission of Ultrananocrystalline diamond. Diamond Relat. Mater. 2002, 11, 43-48.

(30) Sankaran, K. J.; Panda, K.; Sundaravel, B.; Chen, H. C.; Lin, I. N.; Lee, C. Y.; Tai, N. H. Engineering the Interface Characteristics of Ultrananocrystalline Diamond Films Grown on Aucoated Si Substrates. ACS Appl. Mater. Interfaces 2012, 4, 4169-4176. 
(31) Arenal, R.; Bruno, P.; Miller, D. J.; Bleuel, M.; Lal, J.; Gruen, D. M. Diamond Nanowires and the Insulator-Metal Transition in Ultrananocrystalline Diamond Films. Phys. Rev. B 2007, 75, 195431.

(32) Cuenca, J. A.; Sankaran, K. J.; Pobedinskas, P.; Panda, K.; Lin, I. N.; Porch, A.; Haenen, K.; Williams, O. A. Microwave Cavity Perturbation of Nitrogen Doped Nano-crystalline Diamond Films. Carbon 2019, 145, 740-750.

(33) Bhattacharyya, S.; Auciello, O.; Birrell, J.; Carlisle, J. A.; Curtiss, L. A.; Goyette, A. N.; Gruen, D. M.; Krauss, A. R.; Schlueter, J.; Sumant, A.; Zapol, P. Synthesis and Characterization of Highly-Conducting Nitrogen-Doped Ultrananocrystalline Diamond Films. Appl. Phys. Lett. 2001, 79, 1441-1443.

(34) Sankaran, K. J.; Lin, Y. F.; Jian, W. B.; Chen, H. C.; Panda, K.; Sundaravel, B.; Dong, C. L.; Tai, N. H.; Lin, I. N. Structural and Electrical Properties of Conducting Diamond Nanowires. ACS Appl. Mater. Interfaces 2013, 5, 1294-1301.

(35) Sankaran, K. J.; Huang, B. R.; Saravanan, A.; Manoharan, D.; Tai, N. H.; Lin, I. N. Nitrogen Incorporated Ultrananocrystalline Diamond Microstructures from Bias-Enhanced Microwave N2/CH4-Plasma Chemical Vapor Deposition. Plasma Process. Polym. 2016, 13, 419_ 428.

(36) Tzeng, Y.; Yeh, S.; Yang, W. C.; Chu, Y. Nitrogen-Incorporated Ultrananocrystalline Diamond and Multi-Layer-Graphene-like Hybrid Carbon Films. Sci. Rep. 2014, 4, 4531.

(37) Locher, R.; Wild, C.; Herres, N.; Behr, D.; Koidl, P. Nitrogen Stabilized $\langle 100\rangle$ Texture in Chemical Vapor Deposited Diamond Films. Appl. Phys. Lett. 1994, 65, 34-36. 
(38) Ashfold, M. N. R.; Mahoney, E. J. D.; Mushtaq, S.; Truscott, B. S.; Mankelevich, Y. A. What [Plasma used for Growing] Diamond can shine like Flame? Chem. Commun. 2017, 53, 10482-10495.

(39) Li, X.; Perkins, J.; Collazo, R.; Nemanich, R. J.; Sitar, Z. Investigation of the Effect of the Total Pressure and Methane Concentration on the Growth Rate and Quality of Diamond Thin Films Grown by MPCVD. Diamond Relat. Mater. 2006, 15, 1784-1788.

(40) Rakha, S. A.; Yu, G.; Cao, J.; He, S.; Zhou, X. Influence of $\mathrm{CH}_{4}$ on the Morphology of Nanocrystalline Diamond Films Deposited by Ar rich Microwave Plasma. J. Appl. Phys. 2010, $107,114324$.

(41) Williams, O. A.; Douheret, O.; Daenen, M.; Haenen, K.; Osawa, E.; Takahashi, M. Enhanced Diamond Nucleation on Monodispersed Nanocrystalline Diamond. Chem. Phys. Lett. 2007, 445, 255-258.

(42) Sternschulte, H.; Bauer, T.; Schreck, M.; Stritzker, B. Comparison of MWPCVD Diamond Growth at Low and High Process Gas Pressures. Diamond Relat. Mater. 2006, 15, 542-547.

(43) Fowler, R.H.; Nordheim, L. Electron Emission in Intense Electric Fields. Proc. R. Soc. London, Ser. A 1928, 119, 173-181.

(44) Liu, J.; Zhirnov, V. V.; Myers, A. F.; Wojak, G. J.; Choi, W. B.; Hren, J. J.; Wolter, S. D.; McClure, M. T.; Stoner, B. R.; Glass, J. T. Field Emission Characteristics of Diamond Coated Silicon Field Emitters. J. Vac. Sci. Technol. B 1995, 13, 422-426.

(45) Hu, X. J.; Ye, J. S.; Liu, H. J.; Shen, Y. G.; Chen, X. H.; Hu, H. n-type Conductivity and

Phase Transition in Ultrananocrystalline Diamond Films by Oxygen Ion Implantation and Annealing. J. Appl. Phys. 2011, 109, 053524. 
(46) Hu, X. J.; Ye, J. S.; Hu, H.; Chen, X. H.; Shen, Y. G. Phosphorus Ion Implantation and Annealing Induced n-type Conductivity and Microstructure Evolution in Ultrananocrystalline Diamond Films. Appl. Phys. Lett. 2011, 99, 131902.

(47) Sankaran, K. J.; Panda, K.; Sundaravel, B.; Tai, N. H.; Lin, I. N. Enhancing Electrical Conductivity and Electron Field Emission Properties of Ultrananocrystalline Diamond Films by Copper Ion Implantation and Annealing. J. Appl. Phys. 2014, 115, 063701.

(48) Sankaran, K. J; Panda, K.; Sundaravel, B.; Tai, N. H.; Lin, I. N. Catalytically Induced Nanographitic Phase by a Platinum-ion Implantation/Annealing Process to Improve the Field Electron Emission Properties of Ultrananocrystalline Diamond Films. J. Mater. Chem. C 2015, 3, 2632-2641.

(49) Sankaran, K. J.; Srinivasu, K.; Yeh, C. J.; Thomas, J. P.; Drijkoningen, S.; Pobedinskas, P.; Sundaravel, B.; Leou, K. C.; Leung, K. T.; Van Bael, M. K.; Schreck, M.; Lin, I. N.; Haenen, K. Field Electron Emission Enhancement in Lithium Implanted and Annealed Nitrogen Incorporated Nanocrystalline Diamond Films. Appl. Phys. Lett. 2017, 110, 261602.

(50) Panda, K.; Hyeok, J. J.; Park, J. Y.; Sankaran, K. J.; Balakrishnan, S.; Lin, I. N. Nanoscale Investigation of Enhanced Electron Field Emission for Silver Ion Implanted/Postannealed Ultrananocrystalline Diamond Films. Sci. Rep. 2017, 7, 16325.

(51) Mapelli, C.; Castiglioni, C.; Zerbi, G.; Mullen, K. Common Force Field for Graphite and Polycyclic Aromatic Hydrocarbons. Phys. Rev. B 1999, 60, 12710.

(52) Birrell, J.; Gerbi, J. E.; Auciello, O.; Gibson, J. M.; Johnson, J.; Carlisle, J. A. Interpretation of the Raman Spectra of Ultrananocrystalline Diamond. Diamond Relat. Mater. 2005, 14, 86-92.

(53) Ferrari, A. C.; Robertson, J. Interpretation of Raman Spectra of Disordered and Amorphous Carbon. Phys. Rev. B 2000, 61, 14095. 
(54) Malard, L. M.; Pimenta, M. A.; Dresselhaus, G; Dresselhaus, M. S. Raman Spectroscopy in Graphene. Phys. Rep. 2009, 473, 51-87.

(55) Ferrari, A.C. Raman Spectroscopy of Graphene and Graphite: Disorder, Electron-Phonon Coupling, Doping and Nonadiabatic Effects. Solid State Comm. 2007, 143, 47-57.

(56) Sankaran, K. J.; Tai, N. H.; Lin, I. N. Microstructural Evolution of Diamond Films from CH4/H2/N2 Plasma and Their Enhanced Electrical Properties. J. Appl. Phys. 2015, 117, 075303.

(57) Lin, I. N.; Chen, H. C.; Wang, C. S.; Lee, Y. R.; Lee, C. Y. Nanocrystalline Diamond Microstructures from $\mathrm{Ar} / \mathrm{H}_{2} / \mathrm{CH}_{4}$-Plasma Chemical Vapour Deposition. Cryst. Eng.Comm. 2011, 13, 6082-6089.

(58) Xiao, J.; Li, J. L.; Liu, P.; Yang, G. W. A New Phase Transformation Path from Nanodiamond to New-Diamond via An Intermediate Carbon Onion. Nanoscale 2014, 6, 1509815106.

(59) Terranova, M. L.; Manno, D.; Rossi, M.; Serra, A.; Filippo, E.; Orlanducci, S.; Tamburri, E. Self-Assembly of n-Diamond Nanocrystals Into Supercrystals. Crys. Growth Des. 2009, 9, $1245-1249$.

(60) Kovarik, P.; Bourdon, E. B. D.; Prince, R. H. Electron-Energy-Loss Characterization of Laser-deposited a-C, a-C:H, and Diamond Films. Phys. Rev. B:Condens. Matter. 1993, 48, 12123.

(61) Prawer, S.; Peng, J. L.; Orwa, J. O.; McCallum, J. C.; Jamieson, D. N.; Bursill, L. A. Size Dependence of Structural Stability in Nanocrystalline Diamond. Phys. Rev. B 2000, 62, R16360.

(62) Marcus, B.; Mermoux, M.; Vinet, F.; Campargue, A.; Chenevier, M. Relationship between Emission Spectroscopy and Structural Properties of Diamond Films Synthesized by PlasmaAssisted Chemical Vapor Deposition. Surf. Coat. Tech. 1991, 47, 608-617. 
(63) Shigesato, Y.; Boekenhauer, R. E.; Sheldon, B. W. Emission Spectroscopy during DirectCurrent-Biased, Microwave-Plasma Chemical Vapor Deposition of Diamond. Appl. Phys. Lett. 1993, 63, 314-316.

(64) Balestrino, G.; Marinelli, M.; Milani, E.; Paoletti, A.; Paroli, P.; Pinter, I.; Tebano, A. Systematic Investigation of Plasma Emission Spectra during Microwave Diamond Deposition from CH4-CO2 and C2H2-CO2 Gas Mixtures. Diamond Relat. Mater. 1993, 2, 389-392.

(65) May, P.W.; Mankelevich, Yu. A. From Ultrananocrystalline Diamond to Single Crystal Diamond Growth in Hot Filament and microwave Plasma-Enhanced CVD Reactors: A Unified Model for Growth Rates and Grain Sizes. J. Phys. Chem. C 2008, 112, 12432-12441.

(66) Ma, J.; Michael, N.; Ashfold, R.; Mankelevich, Y. A. Validating Optical Emission Spectroscopy as a Diagnostic of Microwave Activated CH4/Ar/H2CH4/Ar/H2 Plasmas used for Diamond Chemical Vapor Deposition. J. Appl. Phys. 2009, 105, 043302.

(67) Eckert, M.; Neyts, E.; Bogaerts, A. Differences between Ultrananocrystalline and Nanocrystalline Diamond Growth: Theoretical Investigation of CxHy Species at Diamond Step Edges. Crys. Growth Des. 2010, 10, 4123-4134.

(68) Sternbergt, M.; Zapol, P.; Frauenheimt, T.; Carlisle, J. A.; Gruen, D. M.; Curtiss, L. A.

Density Functional based Tight Binding Study of C2 and CN Deposition on (100) Diamond Surface. Mat. Res. Soc. Symp. Proc. MRS Proc. 2001, 675, W12.

(69) Kajihara, S. A.; Antonelli, A.; Bernhol, J.; Car, R. Nitrogen and Potential $n$-type Dopants in Diamond. Phys. Rev. Lett. 1991, 66, 2010-2013.

(70) Zapol, P.; Sternberg, M.; Curtiss, L.A.; Frauenheim, T.; Gruen, D. M. Tight-binding Molecular-dynamics Simulation of Impurities in Ultrananocrystalline Diamond Grain Boundaries. Phys. Rev. B 2001, 65, 045403. 
Table 1. Electrical, Field Electron Emission and Microplasma Illumination Properties of NCD films Grown using Various Concentrations of $\mathrm{CH}_{4}$ from 1-15\% in $\mathrm{CH}_{4} / \mathrm{H}_{2} / \mathrm{N}_{2}$ Plasmas.

\begin{tabular}{|c|c|c|c|c|c|c|}
\hline \multirow[b]{2}{*}{ Samples } & \multirow[b]{2}{*}{$\begin{array}{c}\text { Resistivity } \\
\qquad(\Omega \bullet \mathbf{c m})\end{array}$} & \multicolumn{3}{|c|}{ Field electron emission } & \multicolumn{2}{|c|}{ Microplasma illumination } \\
\hline & & $\begin{array}{c}\text { Turn-on } \\
\text { field } \\
(\mathrm{V} / \mu \mathrm{m})\end{array}$ & $\begin{array}{c}\text { FEE current } \\
\text { density } \\
\left(\mathrm{mA} / \mathrm{cm}^{2}\right)\end{array}$ & $\begin{array}{c}\text { Field } \\
\text { enhancement } \\
\text { factor }\end{array}$ & $\begin{array}{l}\text { Threshold } \\
\text { field } \\
\text { (V/cm) }\end{array}$ & $\begin{array}{c}\text { Plasma current } \\
\text { density } \\
\left(\mathbf{m A} / \mathbf{c m}^{2}\right) @ 500 \mathrm{~V}\end{array}$ \\
\hline $\mathrm{NCD}_{1}$ & $1.50 \times 10^{8}$ & 44.0 & $0.08 @ 68.1 \mathrm{~V} / \mu \mathrm{m}$ & 410 & 4100 & 1.13 \\
\hline $\mathrm{NCD}_{5}$ & $2.50 \times 10^{5}$ & 18.8 & $1.5 @ 40.0 \mathrm{~V} / \mu \mathrm{m}$ & 1750 & 3970 & 1.11 \\
\hline $\mathrm{NCD}_{10}$ & $2.0 \times 10^{2}$ & 9.3 & $2.6 @ 19.2 \mathrm{~V} / \mu \mathrm{m}$ & 2315 & 3800 & 1.11 \\
\hline $\begin{array}{c}\mathrm{NCD}_{15} \\
(\mathrm{NDNN})\end{array}$ & $9.0 \times 10^{1}$ & 4.3 & $3.3 @ 8.6 \mathrm{~V} / \mu \mathrm{m}$ & 3865 & 3600 & 1.14 \\
\hline
\end{tabular}




\section{Figure captions}

Figure 1. SEM micrographs with the insets showing the cross-sectional SEM micrographs of NCD films grown using different $\mathrm{CH}_{4}$ concentrations in $\mathrm{CH}_{4} / \mathrm{H}_{2} / \mathrm{N}_{2}$ plasmas (a) $\mathrm{NCD}_{1}$, (b) $\mathrm{NCD}_{5}$, (c) $\mathrm{NCD}_{10}$ and (d) NDNN films. (e) Variation in growth temperature (curve I) and growth rate (curve II) of the NCD films.

Figure 2. (a) Micro-Raman spectra, (b) Linear diffraction patterns, selective area (c) core-loss EELS spectra and (d) plasmon-loss EELS spectra for (I) $\mathrm{NCD}_{1}$, (II) $\mathrm{NCD}_{5}$, (III) $\mathrm{NCD}_{10}$ and (IV) NDNN films. The linear diffraction patterns were deduced from the SAED images of the NCD films shown in the insets of Figure 4(a), 5(a), 6(a) and 7(a), respectively.

Figure 3. (a) Field electron emission (FEE) current density $(J)$ as a function of applied field $(E)$, with inset showing the FN plots, $\ln J / E^{2}-1 / E$ curves, of the corresponding $J$-E characteristic curves and (b) variation in turn-on field ( $E_{0}$, curve I) and field enhancement factor $(\beta$, curve II) of the NCD films with varying $\mathrm{CH}_{4}$ concentrations from 1 to $15 \%$ in $\mathrm{CH}_{4} / \mathrm{H}_{2} / \mathrm{N}_{2}$ plasmas.

Figure 4. (a) Plasma illumination characteristics for the microplasma devices utilizing (I) $\mathrm{NCD}_{1}$, (II) $\mathrm{NCD}_{5}$, (III) NCD 10 and (IV) NDNN films as cathodes. (b) Plasma illumination current density $\left(J_{\mathrm{PI}}\right)$ as a function of applied field (E) of (I) $\mathrm{NCD}_{1}$, (II) $\mathrm{NCD}_{5}$, (III) $\mathrm{NCD}_{10}$ and (IV) NDNN films grown using different $\mathrm{CH}_{4}$ concentrations from 1 to $15 \%$ in $\mathrm{CH}_{4} / \mathrm{H}_{2} / \mathrm{N}_{2}$ plasmas. The inset of Figure 4(b) shows the plasma illumination lifetime stability measurements of NDNN films at a constant applied voltage of $500 \mathrm{~V}$.

Figure 5. (a) Bright field TEM micrograph of $\mathrm{NCD}_{1}$ films grown using $1 \% \mathrm{CH}_{4}$ in $\mathrm{CH}_{4} / \mathrm{H}_{2} / \mathrm{N}_{2}$ plasmas with their corresponding SAED pattern shown as inset and (b) merged dark field TEM 
image of region " $\mathrm{A}_{1}$ " in "a". (c) HRTEM image of region " $\mathrm{A}_{2}$ " in " $\mathrm{a}$ ". The insets (FT⿱艹0A) show the Fourier-transformed image corresponding to the whole structure image in " $\mathrm{c}$ ", whereas the $\mathrm{ft}_{\mathrm{a} 1}$ to $\mathrm{ft}_{\mathrm{a} 3}$ images show the FT images corresponding to regions "a1 to a3", respectively.

Figure 6. (a) Bright field TEM micrograph of $\mathrm{NCD}_{5}$ films grown using $5 \% \mathrm{CH}_{4}$ in $\mathrm{CH}_{4} / \mathrm{H}_{2} / \mathrm{N}_{2}$ plasmas with their corresponding SAED pattern shown as inset and (b) merged dark field TEM images of region " $\mathrm{B}_{1}$ " in "a”. (c) HRTEM image of region " $\mathrm{B}_{2}$ " in "a”. The insets $\left(\mathrm{FT}_{0 \mathrm{~B}}\right)$ show the Fourier-transformed image corresponding to the whole structure image, whereas the $\mathrm{ft}_{\mathrm{b} 1}$ to $\mathrm{ft}_{\mathrm{b} 3}$ images show the FT images corresponding to regions "b1 to b3", respectively.

Figure 7. (a) Bright field TEM micrograph of $\mathrm{NCD}_{10}$ films grown using $10 \% \mathrm{CH}_{4}$ in $\mathrm{CH}_{4} / \mathrm{H}_{2} / \mathrm{N}_{2}$ plasmas with their corresponding SAED pattern shown as inset and (b) merged dark field TEM images of region " $\mathrm{C}_{1}$ " in "a". (c) HRTEM image of region " $\mathrm{C}_{2}$ " in "a". The insets (FToC) show the Fourier-transformed image corresponding to the whole structure image in "c", whereas the $\mathrm{ft}_{\mathrm{c} 1}$ to $\mathrm{ft}_{\mathrm{c} 3}$ images show the FT images corresponding to regions "c1 to c3", respectively.

Figure 8. (a) Bright field TEM micrograph of NDNN films grown using $15 \% \mathrm{CH}_{4}$ in $\mathrm{CH}_{4} / \mathrm{H}_{2} / \mathrm{N}_{2}$ plasmas with their corresponding SAED pattern shown as inset and (b) merged dark field TEM images of region " $\mathrm{D}_{1}$ " in "a". (c) HRTEM image of region " $\mathrm{D}_{2}$ " in "a". The insets (FTOD) show the Fourier-transformed image corresponding to the whole structure image in "c", whereas the $\mathrm{ft}_{\mathrm{d} 1}$ to $\mathrm{ftd}_{3}$ images show the FT images corresponding to regions “d1 to d3", respectively.

Figure 9. (a) The wide range OES spectra and (b) the $\mathrm{C}_{2}$ range OES spectra for the $\mathrm{CH}_{4} / \mathrm{H}_{2} / \mathrm{N}_{2}$ plasmas containing different $\mathrm{CH}_{4}$ concentration. 


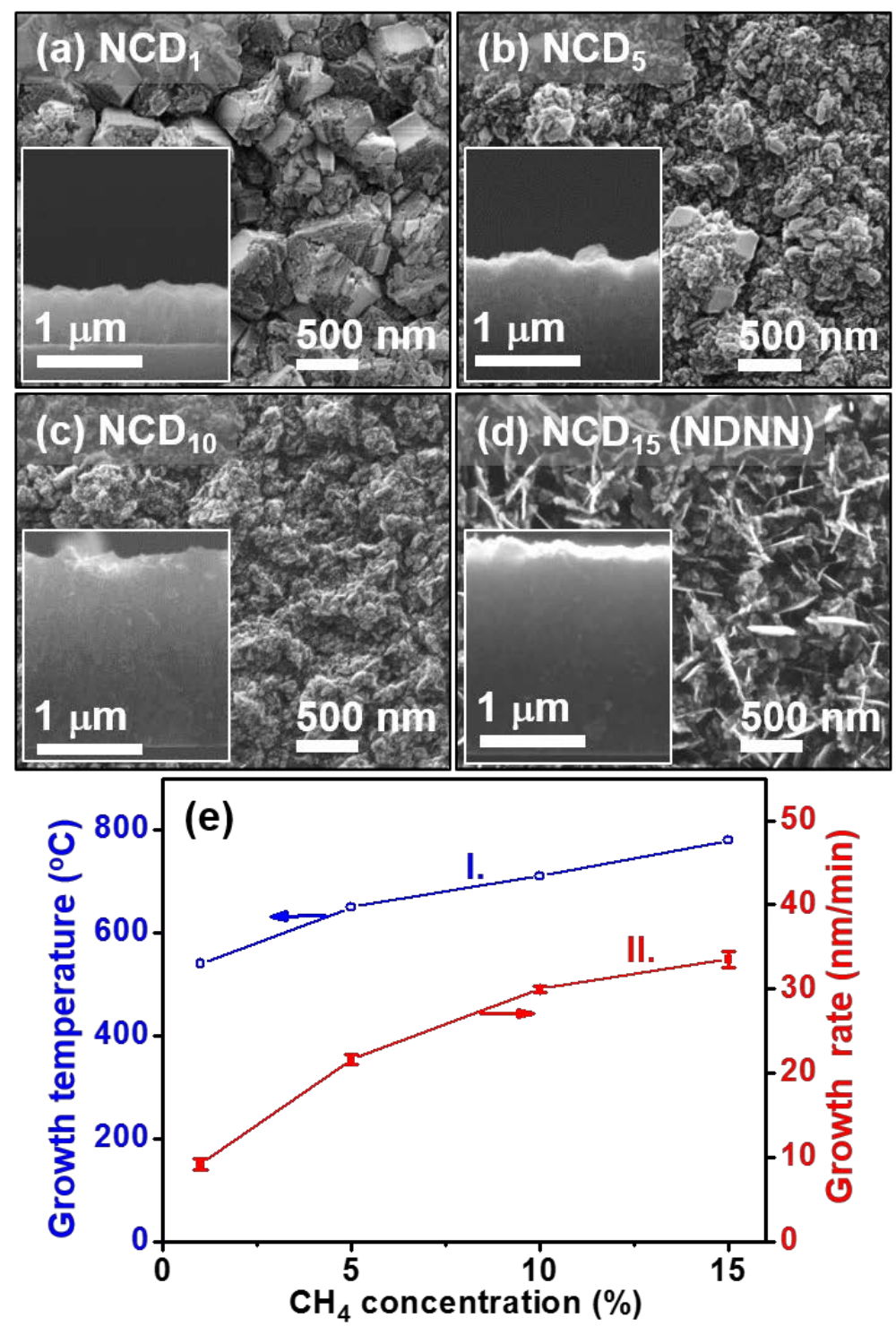

Figure 1. 

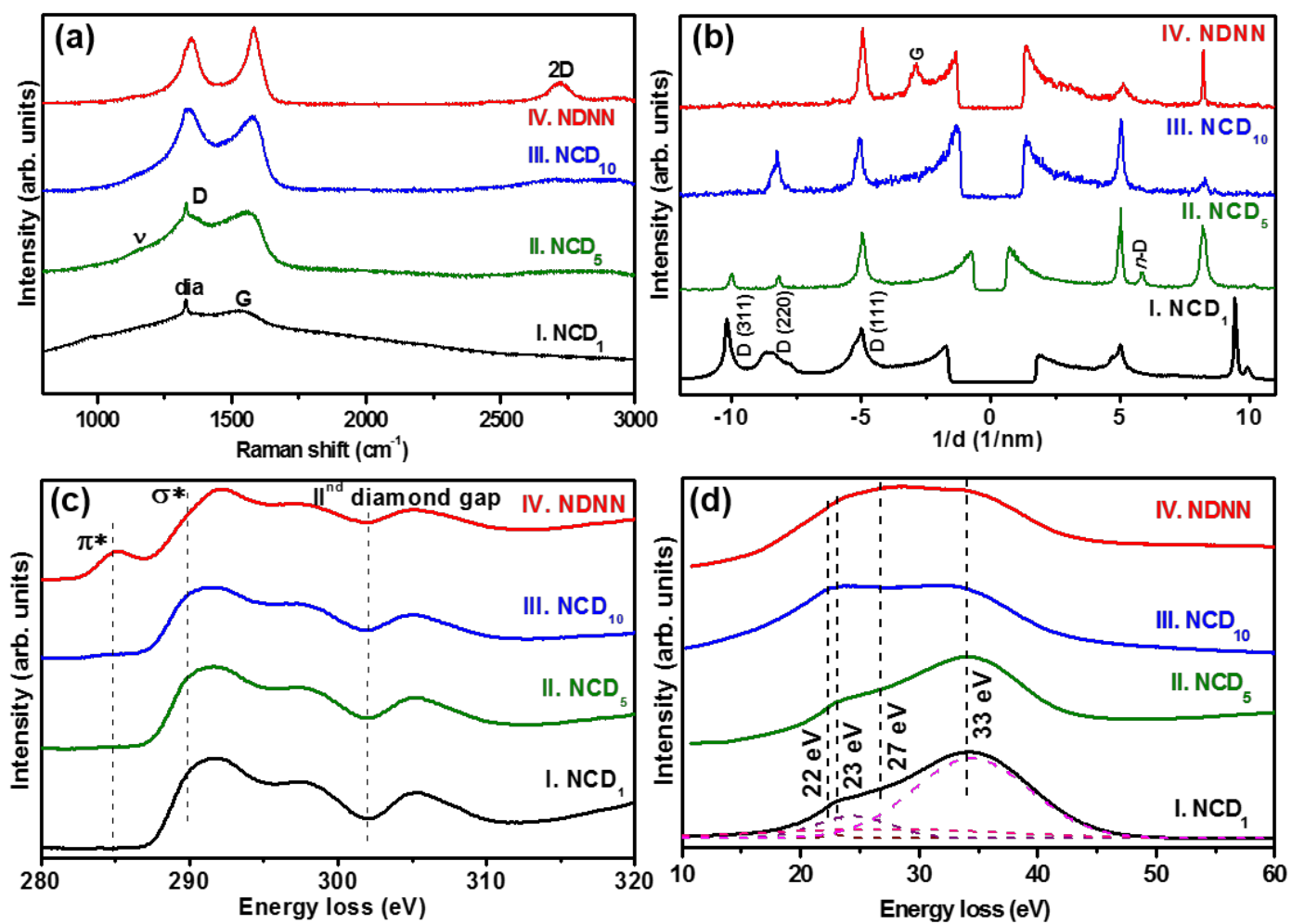

Figure 2. 

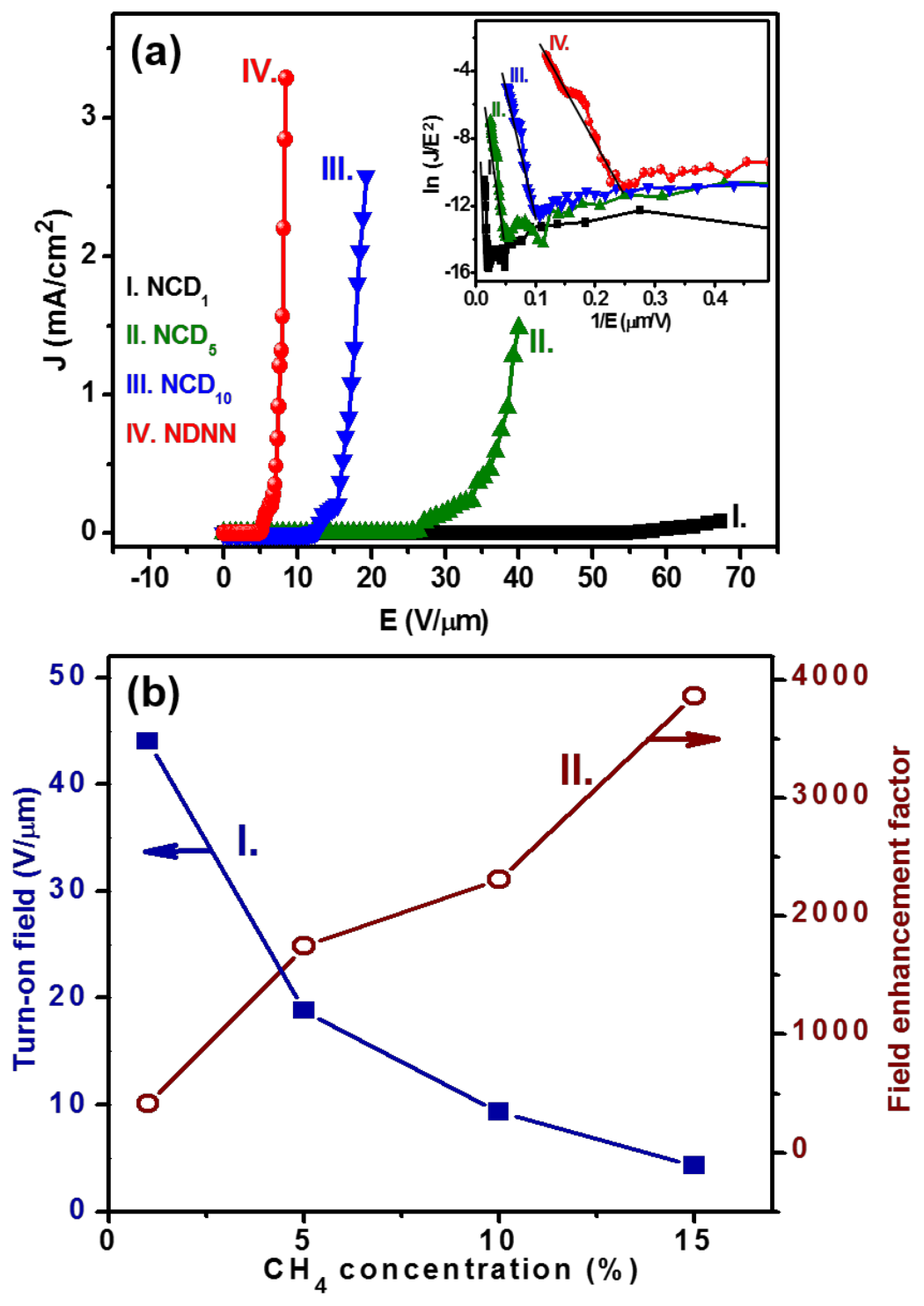

Figure 3. 


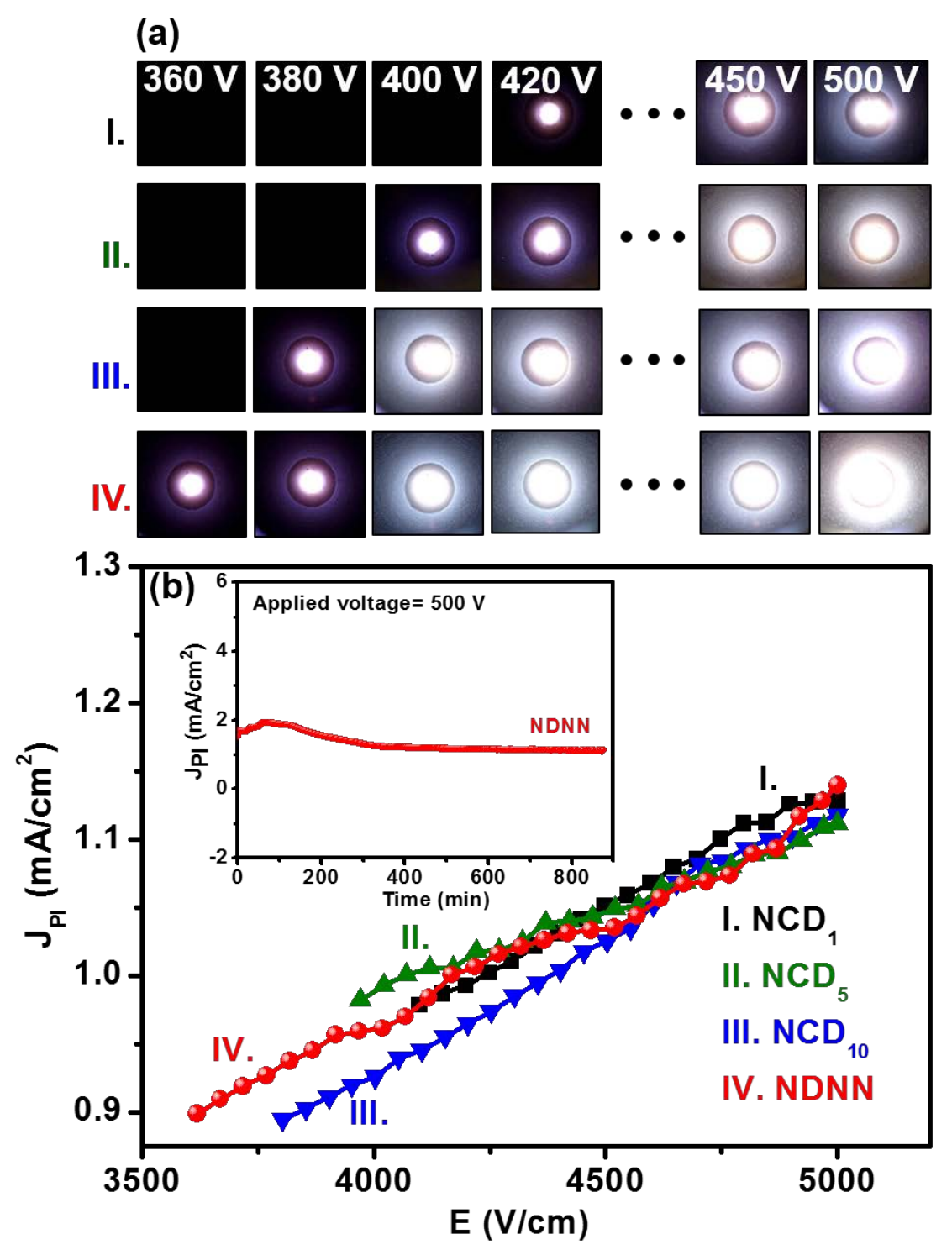

Figure 4. 


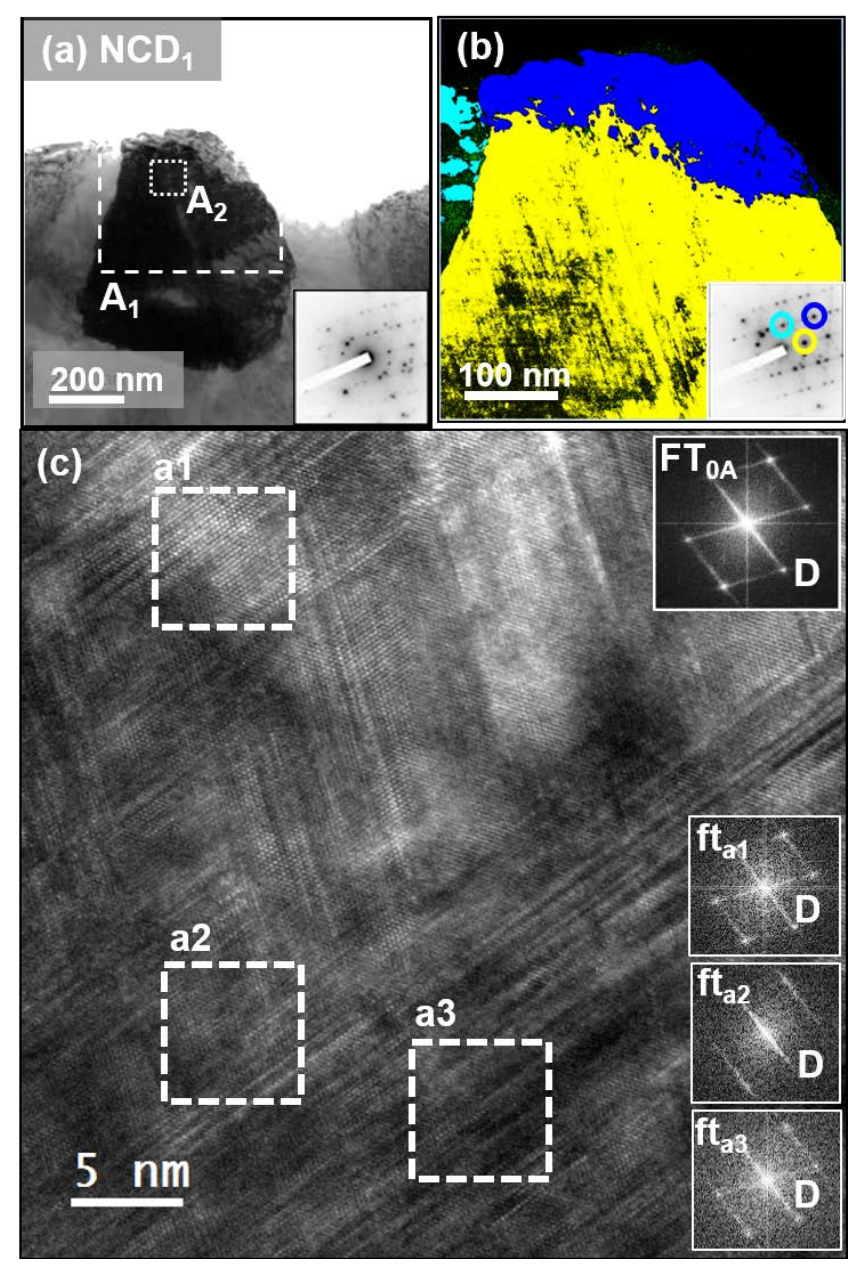

Figure 5. 


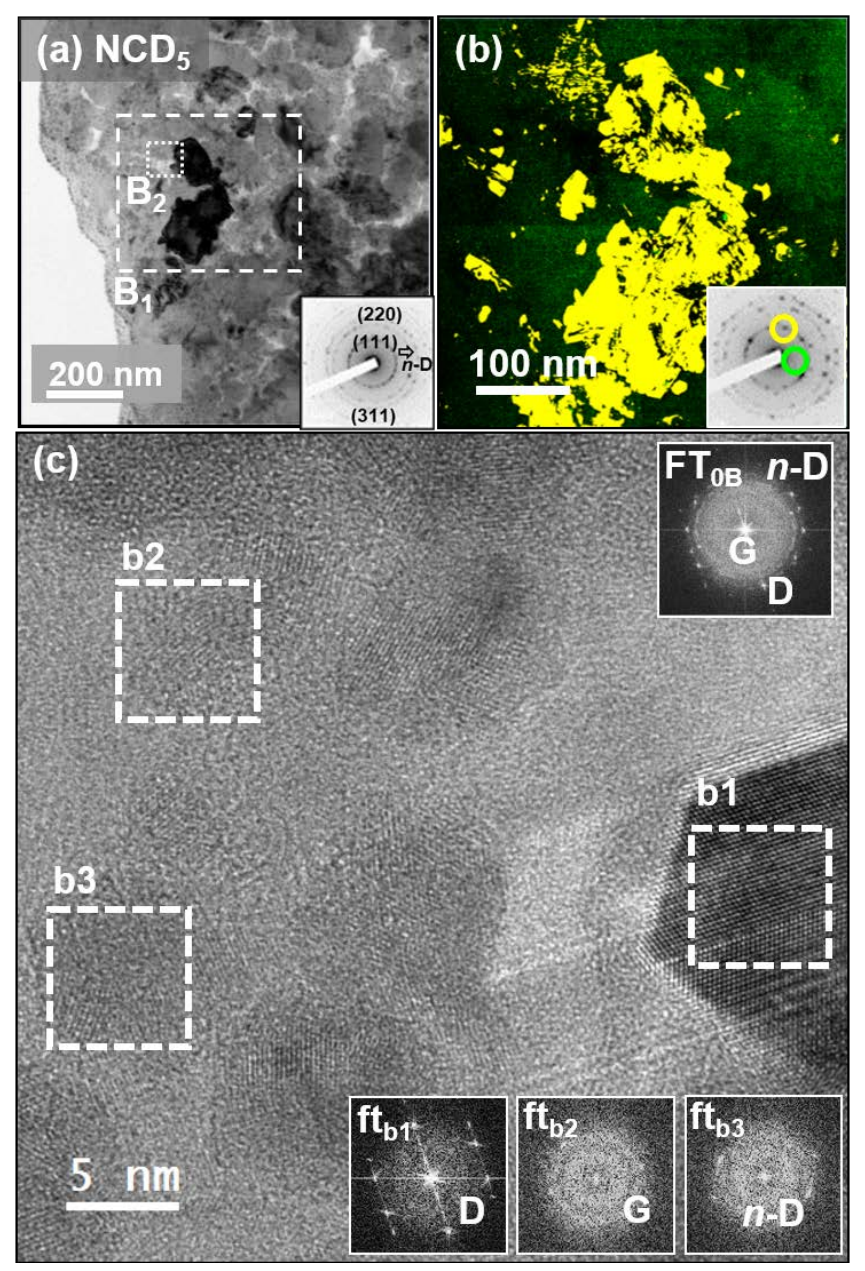

Figure 6. 


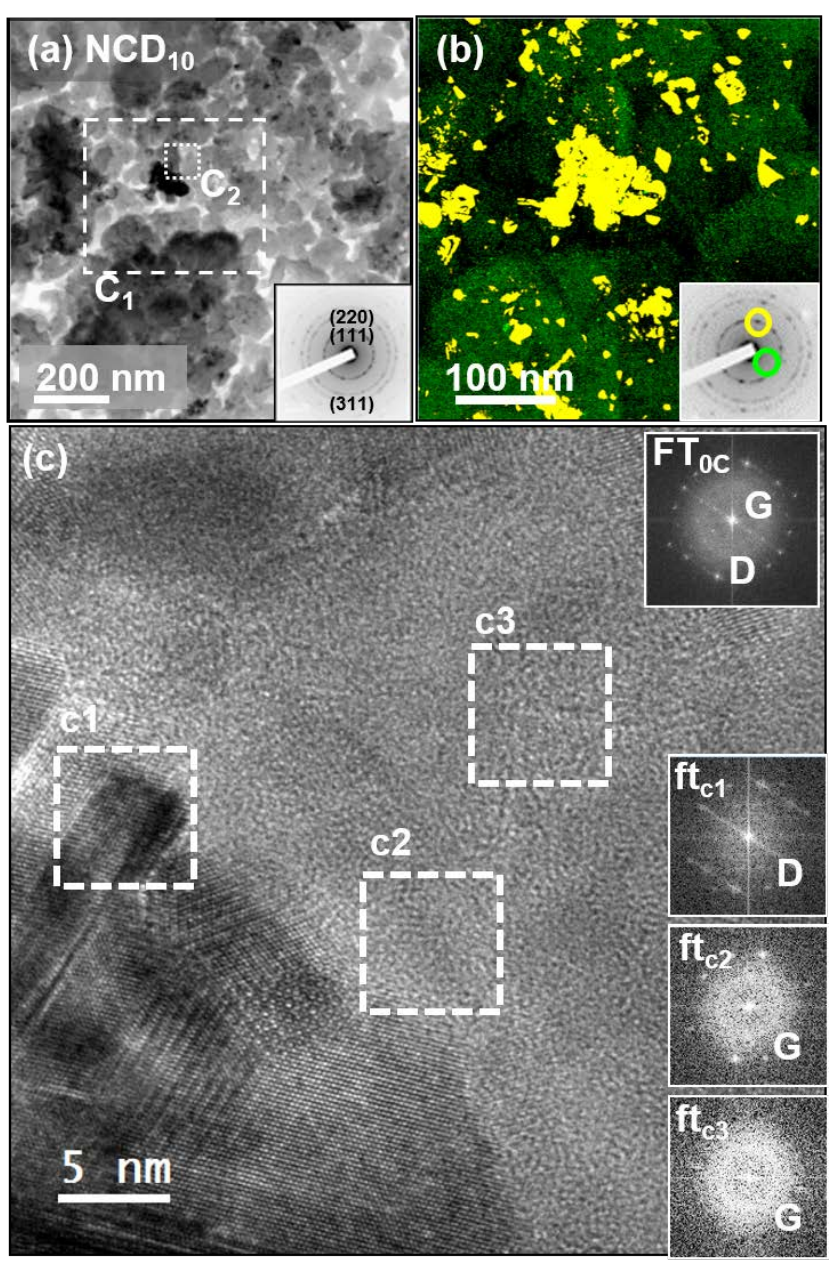

Figure 7. 


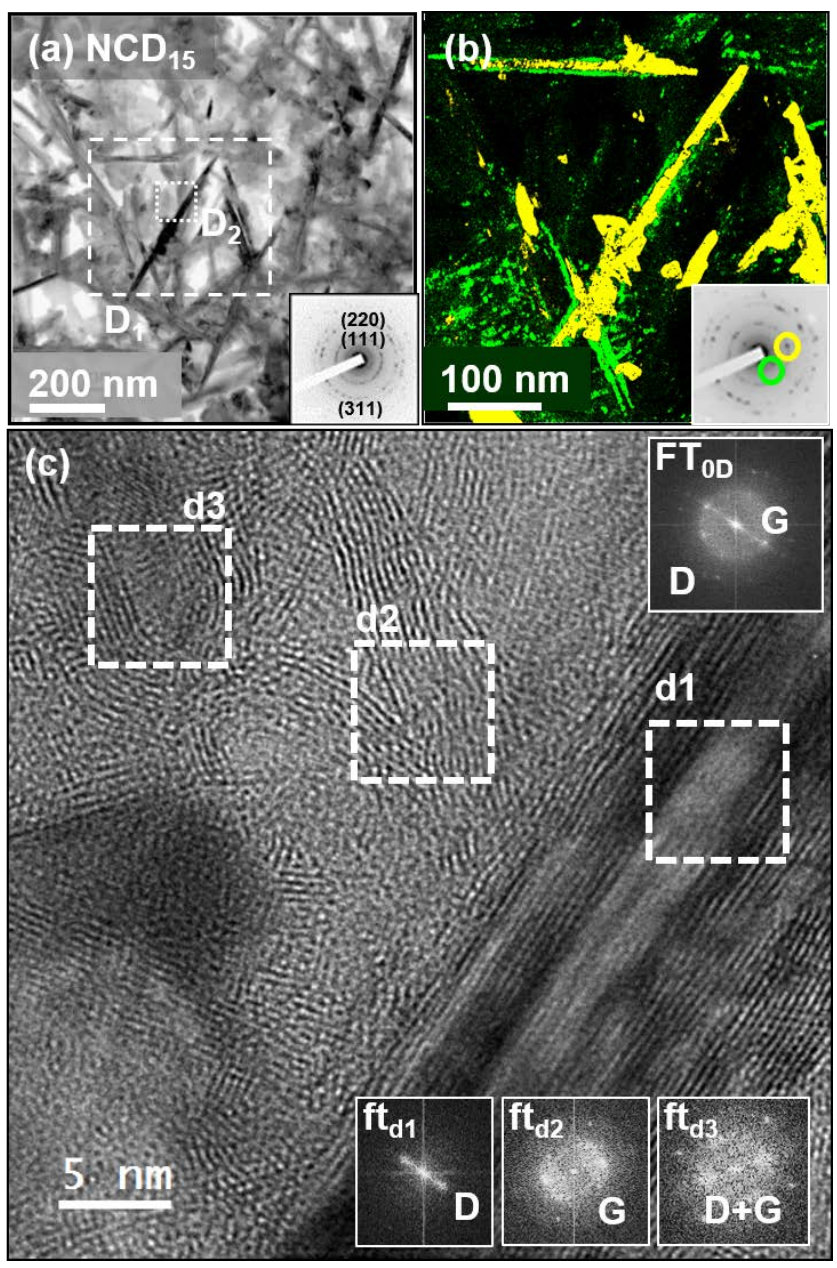

Figure 8. 

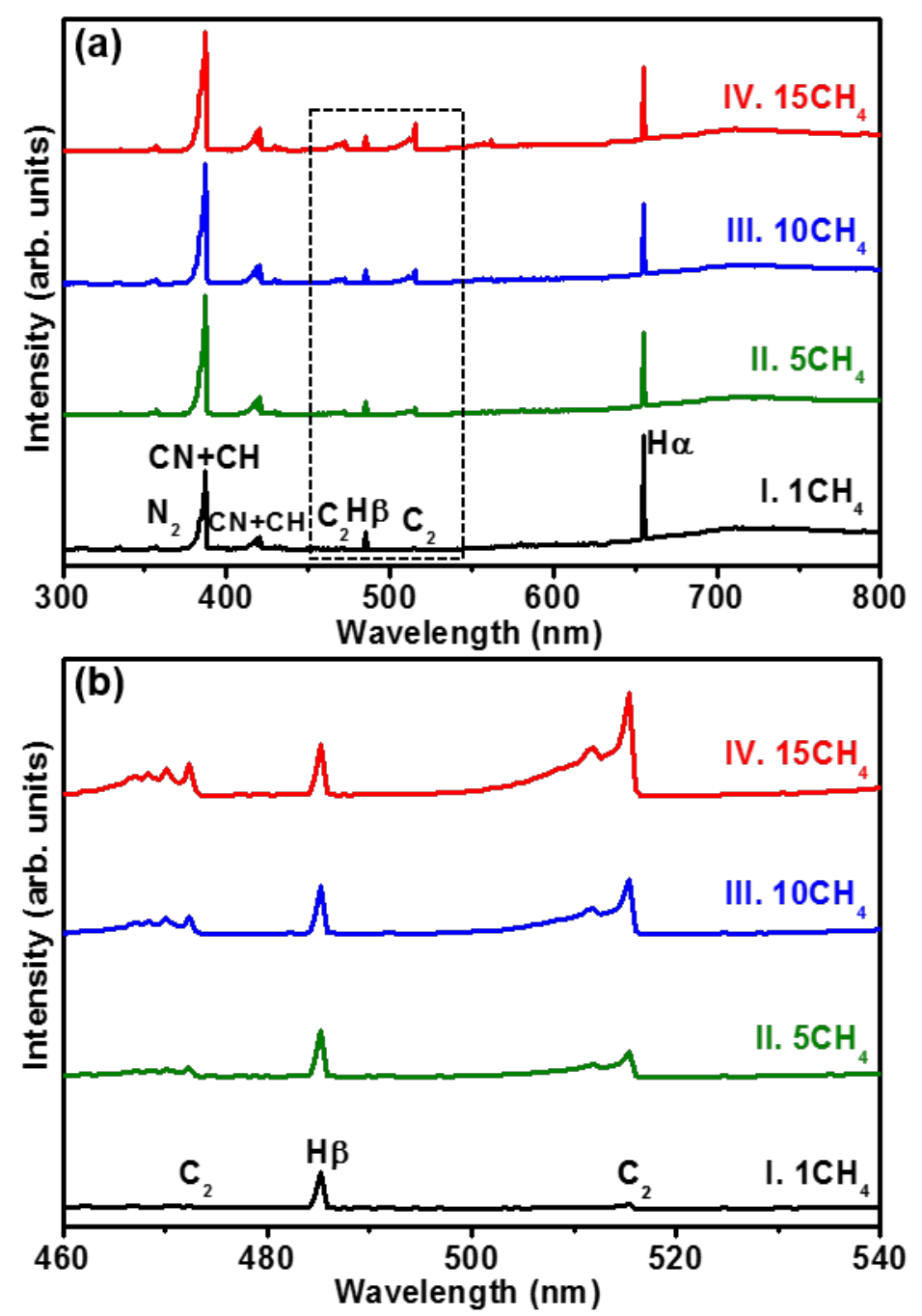

Figure 9. 